\title{
Article \\ Comprehensive Profiling of Mammalian Tribbles Interactomes Implicates TRIB3 in Gene Repression
}

\author{
Miguel Hernández-Quiles ${ }^{1}$, Rosalie Baak ${ }^{1}$, Anouska Borgman ${ }^{1}$, Suzanne den Haan ${ }^{1}$, Paula Sobrevals Alcaraz ${ }^{2}$, \\ Robert van Es ${ }^{2}$, Endre Kiss-Toth ${ }^{3}{ }^{-1}$, Harmjan $\operatorname{Vos}^{2}$ and Eric Kalkhoven $1, *$ (i) \\ 1 Center for Molecular Medicine, University Medical Center Utrecht, Utrecht University, \\ 3584 CG Utrecht, The Netherlands; M.HernandezQuiles-2@umcutrecht.nl (M.H.-Q.); \\ r.e.baak@students.uu.nl (R.B.); A.Borgman-3@umcutrecht.nl (A.B.); s.l.haan@students.uu.nl (S.d.H.) \\ 2 Oncode Institute and Molecular Cancer Research, Center for Molecular Medicine, \\ University Medical Center Utrecht, Utrecht University, 3584 CG Utrecht, The Netherlands; \\ P.SobrevalsAlcaraz-2@umcutrecht.nl (P.S.A.); R.M.vanEs-4@umcutrecht.nl (R.v.E.); \\ H.R.Vos-3@umcutrecht.nl (H.V.) \\ 3 Department of Infection, Immunity and Cardiovascular Disease, Medical School, University of Sheffield, \\ Sheffield S10 2TN, UK; e.kiss-toth@sheffield.ac.uk \\ * Correspondence: e.kalkhoven@umcutrecht.nl; Tel.: +31-887-554-258
}

\section{check for} updates

Citation: Hernández-Quiles, M.; Baak, R.; Borgman, A.; den Haan, S.; Sobrevals Alcaraz, P.; van Es, R.; Kiss-Toth, E.; Vos, H.; Kalkhoven, E. Comprehensive Profiling of Mammalian Tribbles Interactomes Implicates TRIB3 in Gene Repression. Cancers 2021, 13, 6318.

https://doi.org/10.3390/ cancers 13246318

Academic Editor: Jerome Solassol

Received: 2 November 2021

Accepted: 13 December 2021

Published: 16 December 2021

Publisher's Note: MDPI stays neutral with regard to jurisdictional claims in published maps and institutional affiliations.

Copyright: (c) 2021 by the authors Licensee MDPI, Basel, Switzerland. This article is an open access article distributed under the terms and conditions of the Creative Commons Attribution (CC BY) license (https:// creativecommons.org/licenses/by/ $4.0 /)$.
Simple Summary: Tribbles proteins play various roles in cancer initiation and progression. However, still little is known about their molecular actions. Here we developed a mass spectrometry-based approach to study the Tribbles interactomes, allowing us to discover new interactors and functions that might help to understand their behavior better. Our proteomics data highlight the ability of TRIB3 to interact with transcription regulatory proteins and point to a new role in gene repression. Systematic analyses like these will help to evaluate the potential of Tribbles proteins as biomarkers for disease diagnosis and prognosis.

Abstract: The three human Tribbles (TRIB) pseudokinases have been implicated in a plethora of signaling and metabolic processes linked to cancer initiation and progression and can potentially be used as biomarkers of disease and prognosis. While their modes of action reported so far center around protein-protein interactions, the comprehensive profiling of TRIB interactomes has not been reported yet. Here, we have developed a robust mass spectrometry (MS)-based proteomics approach to characterize Tribbles' interactomes and report a comprehensive assessment and comparison of the TRIB1, -2 and -3 interactomes, as well as domain-specific interactions for TRIB3. Interestingly, TRIB3, which is predominantly localized in the nucleus, interacts with multiple transcriptional regulators, including proteins involved in gene repression. Indeed, we found that TRIB3 repressed gene transcription when tethered to DNA in breast cancer cells. Taken together, our comprehensive proteomic assessment reveals previously unknown interacting partners and functions of Tribbles proteins that expand our understanding of this family of proteins. In addition, our findings show that MS-based proteomics provides a powerful tool to unravel novel pseudokinase biology.

Keywords: tribbles; proteomics; interactome; breast cancer

\section{Introduction}

Kinases regulate a plethora of cellular processes and changes in their enzymatic activity are intimately linked to human diseases, hence the large research field studying the basic biology of kinases and their potential as therapeutic targets [1,2]. In addition to 518 kinases, the human genome also encodes $\sim 60$ pseudokinases, proteins that resemble serine/threonine and tyrosine protein kinases but lack several amino acids critical for enzymatic activity $[3,4]$. The human pseudokinase family includes the three members of the Tribbles (TRIB) family-TRIB1, TRIB2 and TRIB3-that share a high degree of 
homology as well as similar domain compositions $[5,6]$. They can be divided into three major domains: an $\mathrm{N}$-terminal domain, associated with protein stability and subcellular localization [7,8]; a well-conserved, centrally located pseudokinase domain; and a Cterminal domain, wherein the binding motifs of MAPK and COP1 are found [9,10]. A fourth, more distally related protein, called STK40, shares important similarities in terms of function and structure [11,12].

Tribbles proteins have been implicated in multiple critical signaling and metabolic processes and alterations in their expression and/or activity is linked to various human diseases [13]. While lacking intrinsic enzymatic activity, Tribbles proteins exert their biological roles predominantly via binding to other proteins, including kinases, phosphatases, transcription factors and components of the ubiquitin-proteosome system [14-16]. This diverse range of interactors explains, at least in part, the difficulties to associate a TRIB family member with a single specific cellular pathway or role. In addition, it should be noted that different and even contradictory observations have been made regarding the subcellular localization of Tribbles proteins, suggesting their localization and thereby function depends on cellular context and conditions $[17,18]$.

In recent years many studies have pointed to Tribbles proteins as important modulators of cancer initiation and progression [19-22]. Therefore, Tribbles proteins hold potential as biomarkers of disease diagnosis and prognosis as well as pharmaceutical targets for a number of cancers [23]. For example, TRIB1 upregulation is significantly associated with metastasis and poor prognosis in prostate cancer [24], it has been shown that TRIB1 mediates radioresistance in glioma cells by an HDAC1-dependent pathway [25] and high levels of TRIB1 are associated with poor breast cancer survival through the regulation of PI3K-NFKB pathway [26]. TRIB2 has been shown to contribute to tumorigenesis in lung cancer through the downregulation of $\mathrm{C} / \mathrm{EBP} \alpha$ [27] and TRIB2 direct interaction with AKT has been shown to be an important mechanism that contributes to resistance to anti-cancer drug therapy [28]. Finally, TRIB3 has been shown to support breast and colorectal cancer stemness through the interaction with AKT and beta-catenin respectively $[29,30]$. These examples illustrate that the different Tribbles family members can all play a regulatory role in cancer initiation and progression, but their contribution may be tumor type specific. Furthermore, these examples also add to anecdotal evidence that critical interacting proteins may differ between Tribbles family members and to previous reports that the affinities of distinct TRIB proteins to the same binding partner may differ [31]. We hypothesize, therefore, that particular Tribbles functions are dictated by its interactome- the specific set of proteins with which a tribble family member is interacting within a given biological setting-and that improving our understanding of how these interactions take place will help to define the roles of Tribbles proteins in each context. To date, comprehensive Tribbles interactomes have not been reported.

Mass spectrometry (MS)-based proteomics approaches have been widely used in recent decades to study and identify protein-protein interactions (PPIs) [32]. Affinitypurification mass spectrometry (AP-MS) is used for the purification of a protein (endogenous or tagged) and its interacting partners from a cell lysate [32]. This technique relies on the affinity of an antibody (or nanobody) for a protein and is followed by MS analysis [32]. We have previously used this approach successfully to identify the interactomes of various intracellular proteins [33-35].

In this study we have developed a robust AP-MS approach to characterize the TRIB1, -2 and -3 interactomes. In addition, we have investigated the contribution of the different domains of TRIB3 to its interactome. Finally, we have generated an inducible system to evaluate the similarities and differences between TRIB1 and -3 interactomes in breast cancer cells as a first proof-of-principle study showing that comprehensive profiling of interactomes can improve our understanding of Tribbles' role in cancer onset and progression. 


\section{Materials and Methods}

2.1. Materials

Primary antibodies anti-turboGFP (Origene, \#TA150041, Rockville, MD, USA), antiGal4DBD (Santa Cruz, sc-510, Santa Cruz, CA, USA) and anti-tubulin (Sigma Aldrich, T9026, St. Louis, MO, USA) were used. Secondary antibodies anti-mouse-HRP (Dako, P0260, Glostrup, Denmark) and anti-rabbit-HRP (Thermofisher, \#31460, Waltham, MA, USA) were used. GFP-Trap and tGFP-Trap Agarose beads (Chromotek, Planegg, Germany) were used for immunoprecipitation. Doxycycline (Sigma Aldrich, D9891).

\subsection{Cell Culture}

Human HEK293T embryonic kidney cell line (ATCC CRL-3216, Manassas, VA, USA) and human MCF7 breast cancer cells (ATCC HTB-22) were maintained in DMEM $4.5 \mathrm{~g} / \mathrm{L}$ d-glucose supplemented with $10 \%$ fetal bovine serum and $1 \%$ penicillin and streptomycin. Cells were incubated in $5 \% \mathrm{CO}_{2}$ incubator at $37^{\circ} \mathrm{C}$ and $95 \%$ humidity. To generate cells stably overexpressing TRIB1 or $-3, \mathrm{MCF} 7$ cells were transduced with third-generation lentiviral constructs using supernatants from HEK293T cells transfected with lentiviral packaging plasmids. HEK293T cells were transfected using X-treme gene 9 DNA transfection reagents (Roche), according to the manufacturer's protocol.

\subsection{Plasmids}

TRIB3 and TRIB1 expression plasmids were kindly provided by Dr. Endre Kiss-Toth. Pcw57.1 lentiviral construct was provided by Dr. S.W.C. van Mil (UMC Utrecht, Utrecht, the Netherlands). Deletions of the N- and C-terminal regions of TRIB3 were performed using a Quickchange mutagenesis kit (Stratagene, San Diego, CA, USA). Successful mutagenesis was verified by Sanger sequence analysis. The reporter construct 5xGAL4-TK-Luc-pGL3 has been described previously [36]. The pCDNA-Gal4DBD-TRIB3 was generated by cloning TRIB3 BamH1/Xba1 fragment from TRIB3 expression plasmid into the respective sites of pCDNA-Gal4DBD as described before [37]. pCDNA-Gal4DBD-TRIB3- $\Delta$ N-terminal (amino acids 69 to 358) and pCDNA-Gal4DBD-TRIB- $\Delta$ C-terminal (amino acids 1 to 316) were generated using Quickchange mutagenesis kit (Stratagene).

\subsection{Luciferase Reporter Assays}

HEK-293T and MCF7 cells were transfected using Xtreme gene 9 DNA transfection reagent (Roche) in 24-well plate format; $100 \mathrm{ng}$ pCDNA3.1-Gal4DBD-TRIB3WT and mutants, $1 \mu \mathrm{g}$ of pGL3 reporter and $2 \mathrm{ng}$ of TK-Renilla luciferase were used for the experiments. After $48 \mathrm{~h}$ cells were lysed and firefly and Renilla luciferase were measured with a Dual-Luciferase Reporter Assay System (Promega, Madison, WI, USA) in a TriStar2 LB942 Multimode Reader (Berthold Technologies, Bad Wildbad, Germany). The results are expressed in relative luciferase units; the results are an average of three independent experiments. Student's $t$-tests were used. Statistical significance was defined as $p<0.05$.

\subsection{Western Blot Analysis}

Western blotting was performed as described before [37] In short, cells were grown in 6-well format or $10-\mathrm{cm}$ dishes. After induction with $2 \mu \mathrm{g} / \mathrm{mL}$ doxycycline for $24 \mathrm{~h}$, cells were washed with ice-cold PBS, twice, and scraped in ice-cold lysis buffer $(150 \mathrm{mM} \mathrm{NaCl}$, $1 \%$ NP40, 0.5\% sodium DOC, 0.1\% SDS, 25 mM Tris pH 7.4) supplemented with protease inhibitors. After incubation on ice for $20^{\prime}$, samples were centrifuged at maximum speed for $10^{\prime}$ at $4^{\circ} \mathrm{C}$ and supernatants were collected. Protein concentrations were measured, samples were supplemented with Laemmli Sample Buffer (LSB) and incubated at $95^{\circ} \mathrm{C}$ for $5^{\prime}$ before use. Samples were separated by SDS-PAGE and then transferred to PVDF membrane. Blocking was performed in 5\% milk in TBS-T for $45^{\prime}$. Incubation with primary antibody was done overnight at $4{ }^{\circ} \mathrm{C}$ and secondary for $1 \mathrm{~h}$ at room temperature. Membranes were treated with ECL Western blot solution and protein expression was detected using LAS4000 Image Quant. 


\subsection{Immunoprecipitation}

HEK293T cells were seeded in $15 \mathrm{~cm}$ dishes and transfected when the cells were approximately at $80 \%$ confluency. Forty-eight hours after transfection cells were washed in ice-cold PBS twice and then scrapped in $2 \mathrm{~mL}$ of lysis buffer $(50 \mathrm{mM}$ Tris $8.0 \mathrm{pH}, 1 \mathrm{mM}$ EDTA pH 8.0, 0.1\% NP40, $250 \mathrm{mM} \mathrm{NaCl}, 10 \%$ Glycerol). Samples were incubated on ice for $20^{\prime}$ and then spun down at maximum speed for $10^{\prime}$ at $4{ }^{\circ} \mathrm{C}$, supernatant was collected. GFP-Trap beads (Chromotek) were equilibrated according to the manufacturer's protocol and incubated with the supernatant from the previous step for $2 \mathrm{~h}$ at $4{ }^{\circ} \mathrm{C}$. Then beads were collected by spinning down the samples at $2500 \mathrm{~g}$ for $5^{\prime}$ at $4^{\circ} \mathrm{C}$. Beads were washed two times with lysis buffer and one final time in PBS before being transferred to a lowbinding Eppendorf tube. Finally, the beads were spun down and dried using a Pasteur pipette. MCF7 cells were induced with $2 \mu \mathrm{g} / \mathrm{mL}$ doxycycline for $24 \mathrm{~h}$ before lysis and incubation with turboGFP-Trap beads (Chromotek) as described above.

\subsection{Confocal Microscopy}

Cells were grown in $\mu$-Slide 8-well glass-bottom chambers (Ibidi) and treated with $2 \mu \mathrm{g} / \mathrm{mL}$ doxycycline for $24 \mathrm{~h}$. Cells were incubated with DAPI (Vectashield) for $10 \mathrm{~min}$ to stain nuclei. Images were obtained using LSM880 Zeiss Microscope.

\subsection{Mass Spectrometry}

The precipitated proteins were denatured and alkylated in $50 \mu \mathrm{L} 8 \mathrm{M}$ Urea, $1 \mathrm{M}$ ammonium bicarbonate containing $10 \mathrm{mM}$ tris (2-carboxyethyl) phosphine hydrochloride and $40 \mathrm{mM}$ 2-chloro-acetamide. After 4-fold further dilution with $1 \mathrm{M}$ ammonium bicarbonate and digestion with trypsin $(250 \mathrm{ng} / 200 \mu \mathrm{L})$, peptides were separated from the sepharose beads and desalted with homemade C-18 stage tips ( $3 \mathrm{M}$, St Paul, MN, USA). Peptides were eluted with $80 \% \mathrm{ACN}$ and, after evaporation of the solvent in the speedvac, redissolved in buffer A ( $0.1 \%$ formic acid). After separation on a 30-cm pico-tip column (75 $\mu \mathrm{m}$ ID, New Objective) in-house packed with C-18 material (1.9 $\mu \mathrm{m}$ aquapur gold, dr. Maisch) using a 140-min gradient (7\% to $80 \%$ ACN, $0.1 \%$ FA), delivered by an easy-nLC 1000 (Thermo), peptides were electro-sprayed directly into an Orbitrap Fusion Tribrid Mass Spectrometer (Thermo Scientific). The MS was run in DDA mode with a cycle time of $1 \mathrm{~s}$, in which the full scan (400-1500 mass range) was performed at a resolution of 240,000. Ions reaching an intensity threshold of 10,000 were isolated by the quadrupole and fragmented with an HCD collision energy of $30 \%$.

The obtained raw data was analyzed with MaxQuant [version 1.6.3.4], using the Uniprot fasta file (UP000005640) of Homo sapiens (taxonomy ID: 9606), extracted at 21/01/2021. Minimum and maximum peptide lengths of 7 and 25 amino acids respectively, with Oxidation on Methionine and Acetylation on Protein N-term as variable modifications and Carbamidomethyl on Cysteine as a fixed modification. Peptide and protein false discovery rates were set to $1 \%$.

To determine proteins of interest, we performed a differential enrichment analysis on the generated Maxquant output. First, we generated unique names for the genes associated to multiple proteins to be able to match them. Second, we filtered for proteins that were identified in at least three out of four of the replicates of one condition. Then, we background corrected and normalized the data by variance stabilizing transformation; shifting and scaling the proteins intensities by sample group. We used a left-shifted Gaussian distribution to impute for missingness, since our data presented a pattern of missingness not at random (MNAR). Finally, we performed a differential enrichment analysis to identify those proteins that were over-enriched and selected those with at least a 2.5 -fold change and adjusted $p$-value $\leq 0.05$. The adjusted $p$-value was calculated using the Benjamin-Hochberg procedure. The program used for the analyses was $\mathrm{R}$ [version 4.0.4] through R-Studio [version 1.5.64]. The mass spectrometry proteomics data have been deposited to the ProteomeXchange Consortium via the PRIDE partner repository 
(Available online: http:/ / www.ebi.ac.uk/pride (accessed on 15 December 2021). Dataset identifiers will be provided during review.

\section{Results}

\subsection{Analysis of TRIB1, TRIB2 and TRIB3 Interactomes in HEK293T Cells Using AP-MS}

To better understand the distinct role of each Tribbles family member, as well as their redundancies, we developed a method to robustly identify Tribbles interactomes. We transiently overexpressed TRIB1, TRIB2 and TRIB3 as GFP-fusion proteins in HEK293T cells and performed AP-MS experiments. We used nanobodies against GFP to purify Tribbles proteins and their interacting partners, which allowed us to reduce background binding and minimize the amount of peptides released during on-bead digestion [38]. After purification we used liquid chromatography-tandem mass spectrometry (LC-MS) to characterize Tribbles interactomes (Figure 1A).

Among the different interactors that were found we could detect the known binding partners of TRIB1, TRIB2 and TRIB3 as well as interactors that have not yet been reported. The results are described in Tables 1-3. As reported before [9,39], all Tribbles family members were able to physically interact with the E3 ubiquitin degradation complex formed by the ubiquitin E3 ligase COP1 and the adaptors proteins DET1 and DDB1. Confirming the specificity of our methodology, we mutated the COP1 binding motif (Figure 1A) and thus specifically depleted the interactome from COP1 and DET1 (Figure 1B,D). TRIB1 and TRIB2 were found to interact with TRIB1 and the Tribbles-related pseudokinase STK40, suggesting that Tribbles proteins can form homo- and heterodimers in mammalian cells, as has been shown for the Drosophila Tribbles homologue Trbl [40] and for the mammalian versions in protein complementation assays (PCA; unpublished observations). Other previously described interaction partners that were detected included activating transcription factor 4 (ATF4) [41]. While not previously described as binding partners, the mTOR regulatory subunits RICTOR and RAPTOR were also detected in the TRIB2 interactome (Figure 1C). Previous studies have shown, however, that TRIB2 regulates mTOR signaling [42,43]. Interactions that have not been described earlier included the interaction between TRIB3 and the mitochondrial transporter TIM-TOM complex, a complex found in the mitochondrial membrane that transports proteins into the inner membrane of the mitochondria [44]. In addition, whilst the interaction between TRIB proteins and the E3 ubiquitin ligase COP1 is well-established [9,45], TRIB1 and TRIB3 showed interaction with another family of E3 ubiquitin ligases, that includes STIP1 and STUB1. Among the most enriched interactors of TRIB2 were SKT and BDH2, two interaction partners, newly identified here, that are involved in the development of different tissues and an enzyme involved in metabolism, respectively [46,47]. In summary, the identification of known interactors of Tribbles validates our experimental approach and provides support for the newly discovered binding partners.

A
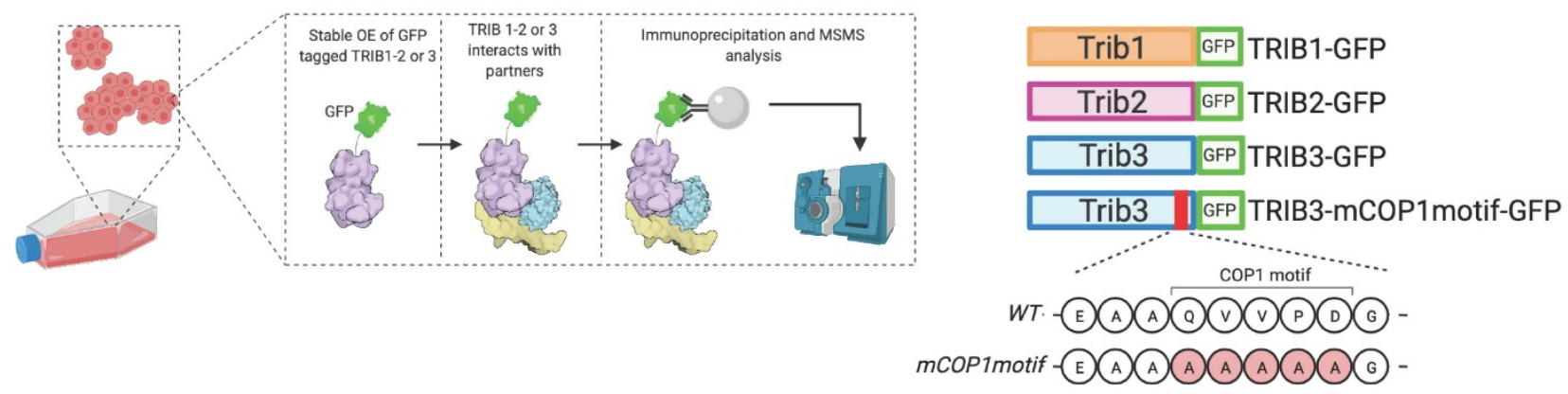

Figure 1. Cont. 
B

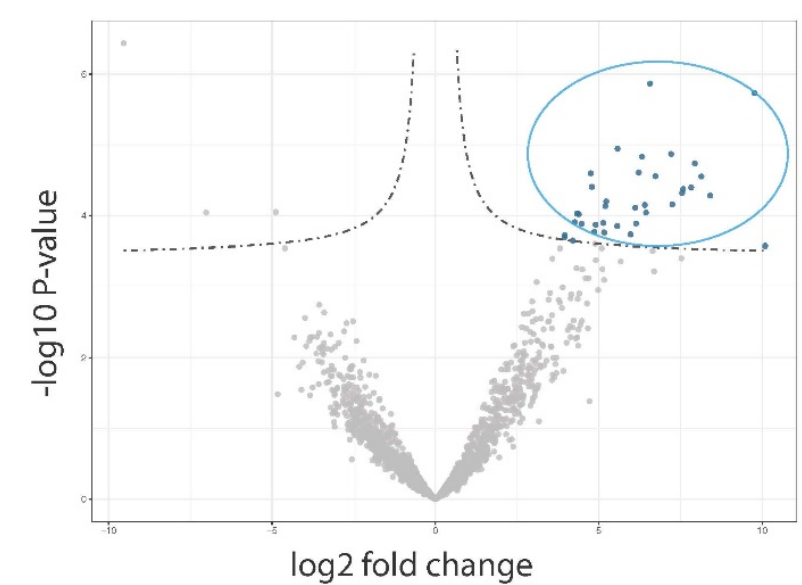

C

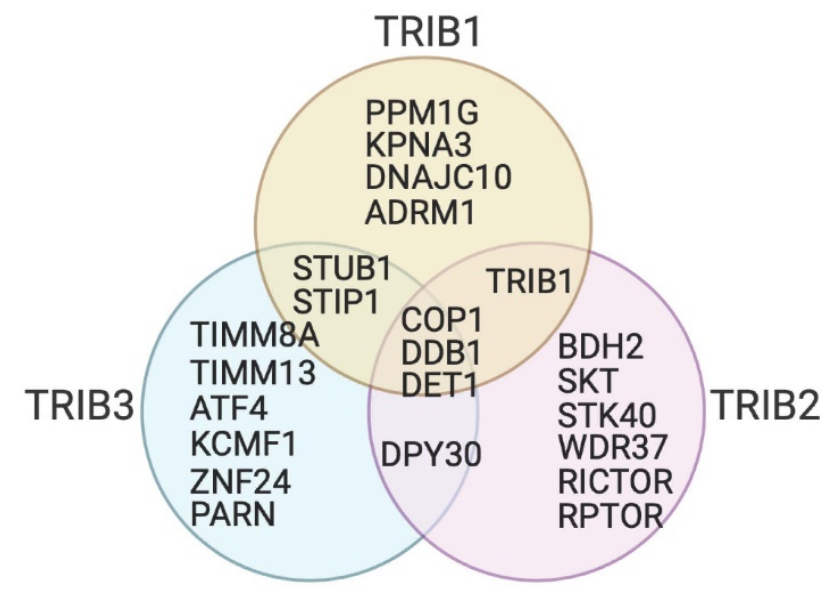

TRIB3-mCOP1 vs TRIB3 WT

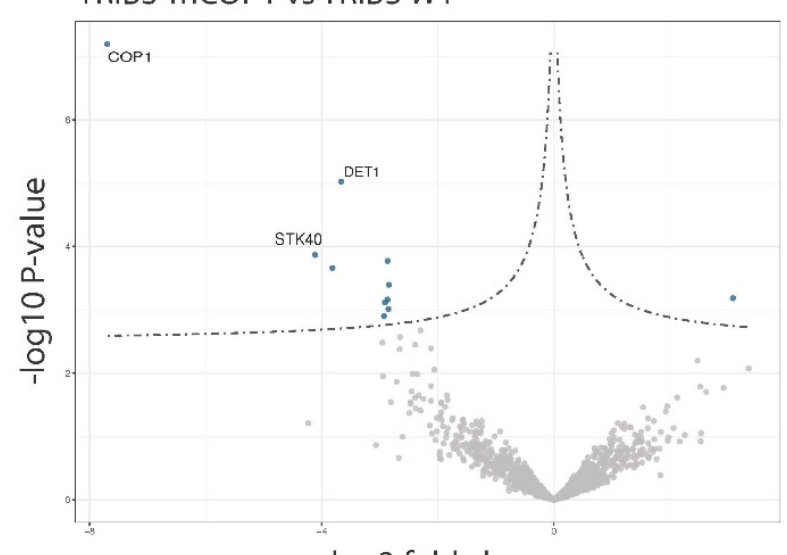

$\log 2$ fold change

D

Figure 1. TRIB1, -2 and -3 interactomes in HEK293T cells. (A) Schematic representation of workflow followed for APMS experiments. Figure was created with BioRender.com. (B) Volcano plots showing TRIB3 interactors compare to GFP control and TRIB3-mCOP1 interactors compared to WT TRIB3 in HEK293T cells. (C) Venn diagram of common and unique interactors between Tribbles family members. (D) TRIB3 interactors lost when comparing TRIB3 vs TRIB3mCOP1 interactomes.

Table 1. Top 25 TRIB1 interacting partners in HEK293T cells based on $p$-value.

\begin{tabular}{ccccc}
\hline Gene Name & -Log $(p$-Value $)$ & Adjusted $p$-Value & Log2 Fold Change * & Full Name \\
\hline DNAJC10 & 6.4354 & $6.18 \times 10^{-5}$ & 7.300 & $\begin{array}{c}\text { DnaJ Heat Shock Protein Family } \\
\text { Member C10 }\end{array}$ \\
\hline DDB1 & 5.8200 & 0.04 & 4.678 & Damage Specific DNA Binding Protein 1 \\
\hline TRIB1 & 5.7117 & $8.17 \times 10^{-7}$ & 2.567 & Tribbles Pseudokinase 1 \\
\hline PPM1G & 5.2926 & 0.02 & 6.113 & Protein Phosphatase Mg ${ }^{2+}$ Dependent 1G \\
\hline PSMA1 & 5.2130 & $5.29 \times 10^{-5}$ & 4.699 & Proteosome 20S subunit Alpha 1 \\
\hline PSMA2 & 5.0433 & 0.0002 & 3.443 & Proteosome 20S subunit Alpha 2 \\
\hline PSMD4 & 5.0242 & 0.0004 & 3.112 & Proteasome 26S Subunit Ubiquitin \\
receptor 4
\end{tabular}


Table 1. Cont.

\begin{tabular}{|c|c|c|c|c|}
\hline Gene Name & -Log ( $p$-Value $)$ & Adjusted $p$-Value & Log2 Fold Change * & Full Name \\
\hline PSMC2 & 4.3112 & $4.68 \times 10^{-5}$ & 2.554 & Proteosome 26S subunit ATPase 2 \\
\hline PSMB6 & 4.1668 & 0.006 & 6.433 & Proteosome $20 \mathrm{~S}$ subunit Beta 7 \\
\hline STIP1 & 3.9432 & 0.01 & 4.001 & Stress induced Phosphoprotein 1 \\
\hline PSMB2 & 3.9126 & $1.70 \times 10^{-5}$ & 3.333 & Proteosome 20S subunit Beta 2 \\
\hline STUB1 & 3.8218 & 0.05 & 5.677 & $\begin{array}{l}\text { STIP1 Homology and U-Box Containing } \\
\text { Protein } 1\end{array}$ \\
\hline PSMC1 & 3.7980 & $9.63 \times 10^{-6}$ & 3.655 & Proteosome 20S subunit Beta 7 \\
\hline HSPH1 & 3.6860 & 0.004 & 5.911 & Heat Shock Protein Family H Member 1 \\
\hline KPNA4 & 3.6243 & 0.001 & 3.770 & Karyopherin Subunit Alpha 4 \\
\hline DET1 & 3.5614 & $5.29 \times 10^{-5}$ & 3.190 & $\begin{array}{l}\text { DET } 1 \text { Partner of COP1 E3 } \\
\text { Ubiquitin Ligase }\end{array}$ \\
\hline HSPA4L & 3.4984 & 0.003 & 4.675 & $\begin{array}{l}\text { Heat Shock Protein Family A Member } \\
\qquad 4 \text { Like }\end{array}$ \\
\hline RFWD2 & 3.3768 & 0.0004 & 9.453 & COP1 E3 Ubiquitin Ligase \\
\hline PSMA5 & 3.3478 & 0.0004 & 2.724 & Proteosome $20 \mathrm{~S}$ subunit Alpha 5 \\
\hline HSPA4 & 3.0482 & $1.30 \times 10^{-5}$ & 5.119 & Heat Shock Protein A Member 4 \\
\hline PSMA7 & 3.0482 & 0.003 & 3.880 & Proteosome 20S subunit Alpha 7 \\
\hline KPNA3 & 2.7785 & 0.001 & 4.654 & Karyopherin Subunit Alpha 3 \\
\hline
\end{tabular}

Table 2. Top 25 TRIB22 interacting partners in HEK293T cells based on $p$-value.

\begin{tabular}{|c|c|c|c|c|}
\hline Gene Name & -Log ( $p$-Value) & Adjusted $p$-Value & Log2 Fold Change * & Full Name \\
\hline TRIB1 & 5.771 & $2.76 \times 10^{-5}$ & 12.364 & Tribbles Pseudokinase 1 \\
\hline USP11 & 5.541 & 0.001 & 4.356 & Ubiquitin Specific Peptidase 11 \\
\hline ISCA1 & 5.391 & 0.0002 & 6.115 & IRON-Sulfur Cluster Assembly 1 \\
\hline$B D H 2$ & 4.951 & $3.90 \times 10^{-6}$ & 8.657 & 3-Hydroxybutyrate Dehtdrogenase 2 \\
\hline ZKSCAN1 & 4.945 & 0.0001 & 6.503 & $\begin{array}{c}\text { Zinc Finger with KRAB and SCAN } \\
\text { Domains } 1\end{array}$ \\
\hline DET1 & 4.885 & $3.4 \times 10^{-5}$ & 7.812 & $\begin{array}{c}\text { DET } 1 \text { Partner of COP1 E3 } \\
\text { Ubiquitin Ligase }\end{array}$ \\
\hline DDB1 & 4.523 & 0.001 & 4.456 & Damage Specific DNA Binding Protein 1 \\
\hline AIFM1 & 4.274 & $3.27 \times 10^{-5}$ & 4.898 & $\begin{array}{l}\text { Apoptosis inducing Factor Mitochondrial } \\
\text { Associated } 1\end{array}$ \\
\hline $\mathrm{FECH}$ & 4.262 & $2.76 \times 10^{-5}$ & 5.878 & Ferrochelatase \\
\hline WDR37 & 4.007 & 0.001 & 7.058 & WD Repeat Domain 37 \\
\hline KIAA1217 & 3.789 & 0.001 & 9.837 & Sickle tail Protein Homolog \\
\hline KCTD21 & 3.751 & 0.002 & 3.573 & $\begin{array}{l}\text { BTB/POZ Domain-Containing } \\
\text { Protein KCTD21 }\end{array}$ \\
\hline CDC42EP1 & 3.686 & 0.0003 & 3.082 & CDC42 Effector Protein 1 \\
\hline MLF2 & 3.471 & 0.0003 & 4.887 & Myeloid Leukemia factor 1 \\
\hline STK40 & 3.231 & 0.0001 & 7.644 & Serine/Threonine Kinase 40 \\
\hline$R A B 3 G A P 1$ & 3.218 & 0.0002 & 3.543 & $\begin{array}{l}\text { RAB3 GTPase Activating Protein Catalytic } \\
\text { Subunit } 1\end{array}$ \\
\hline
\end{tabular}


Table 2. Cont.

\begin{tabular}{|c|c|c|c|c|}
\hline Gene Name & -Log ( $p$-Value $)$ & Adjusted $p$-Value & Log2 Fold Change * & Full Name \\
\hline$E M D$ & 3.153 & 0.01 & 4.316 & Emerin \\
\hline RFWD2 & 3.034 & 0.002 & 10.620 & COP1 E3 Ubiquitin Ligase \\
\hline RPTOR & 2.864 & 0.002 & 2.346 & $\begin{array}{l}\text { Regulatory Associated Protein of MTOR } \\
\text { Complex } 1\end{array}$ \\
\hline FKBP4 & 2.841 & 0.01 & 4.293 & FKBP Prolyl Isomerase 4 \\
\hline SRCIN1 & 2.762 & 0.0004 & 4.617 & SRC Kinase Signaling Inhibitor 1 \\
\hline$P K P 2$ & 2.646 & 0.0004 & 4.004 & Plakophilin 2 \\
\hline TBC1D4 & 2.634 & 0.001 & 2.375 & TBC1 Domain Family Member 4 \\
\hline HAUS8 & 2.163 & 0.002 & 3.115 & HAUS Augmin Like Complex Subunit 8 \\
\hline RICTOR & 1.999 & 0.001 & 2.706 & $\begin{array}{l}\text { RPTOR Independent Companion of } \\
\text { MTOR Complex } 2\end{array}$ \\
\hline
\end{tabular}

${ }^{*}$ Log 2-fold change calculated using mean intensity of TRIB2 condition compared to GFP.

Table 3. Top 25 TRIB3 interacting partners in HEK293T cells based on $p$-value.

\begin{tabular}{|c|c|c|c|c|}
\hline Gene Name & -Log ( $p$-Value) & Adjusted $p$-Value & Log2 Fold Change * & Full Name \\
\hline TIMM13 & 7.1286 & 0.0002 & 12.187 & Translocase of Inner Mitochondrial Membrane 13 \\
\hline TRIM37 & 6.9472 & 0.006 & 6.961 & Tripartite Motif Containing 37 \\
\hline DDB1 & 6.2442 & 0.005 & 5.187 & Damage Specific DNA Binding Protein 1 \\
\hline KCMF1 & 5.7442 & 0.007 & 5.885 & Potassium Channel Modulatory Factor 1 \\
\hline ATF4 & 5.7130 & 0.01 & 1.345 & Activating Transcription factor 4 \\
\hline STUB1 & 5.4533 & 0.03 & 5.972 & STIP1 Homology and U-Box Containing Protein 1 \\
\hline MLLT11 & 5.0745 & 0.002 & 6.917 & MLLT11 Transcription factor 7 Cofactor \\
\hline RFWD2 & 5.0033 & 0.0006 & 2.489 & COP1 E3 Ubiquitin Ligase \\
\hline PARN & 4.9405 & 0.01 & 7.321 & Poly(A)-Specific Ribonuclease \\
\hline PRKD2 & 4.6601 & 0.001 & 7.015 & Protein kinase D2 \\
\hline PASK & 4.6442 & 0.005 & 8.091 & $\begin{array}{l}\text { PAS Domain Containing } \\
\text { Serine/Threonine Kinase }\end{array}$ \\
\hline DPY30 & 4.3027 & 0.04 & 5.462 & Dpy-30 Histone Methyltransferase Complex \\
\hline DET1 & 4.1258 & 0.04 & 5.134 & DET 1 Partner of COP1 E3 Ubiquitin Ligase \\
\hline ZNF24 & 4.0712 & 0.001 & 4.125 & Zinc Finger Protein 24 \\
\hline EP300 & 3.9599 & 0.01 & 6.900 & E1A Binding Protein P300 \\
\hline STIP1 & 3.9000 & 0.020 . & 3.582 & Stress induced Phosphoprotein 1 \\
\hline KANK2 & 3.7899 & 0.16 & 6.740 & KN Motif Ankyrin Repeat Domains 2 \\
\hline RBBP8 & 3.7371 & 0.019 & 7.875 & RB Binding Protein 8 \\
\hline ZNF507 & 3.6606 & 0.006 & 7.112 & Zinc Finger Protein 507 \\
\hline PPP6C & 3.5073 & 0.03 & 7.964 & Protein Phosphatase 6 Catalytic Subunit \\
\hline WDR62 & 3.5072 & 0.006 & 7.074 & WD Repeat Domain 62 \\
\hline PPP6R3 & 3.4224 & 0.003 & 7.112 & Protein Phosphatase 6 Regulatory Subunit 3 \\
\hline AKAP8L & 2.7110 & 0.0005 & 8.183 & A-Kinase Anchoring Protein 8 Like \\
\hline ZNF655 & 2.6525 & 0.01 & 6.810 & Zinc Finger Protein 655 \\
\hline TIMM8A & 2.6021 & $3.48 \times 10^{-5}$ & 12.262 & Translocase of Inner Mitochondrial Membrane 8A \\
\hline
\end{tabular}




\subsection{Contribution of the Different Domains to the TRIB3 Interactome}

Tribbles proteins contain three distinct domains, with the central pseudokinase domain being the most conserved; the amino acid sequence of human TRIB1/2 and 3 shows a $55 \%$ similarity in the pseudokinase domain, but, for example, the C-terminal domains of TRIB3 and TRIB1 are only 9\% similar (Supplementary Figure S1). This low similarity in the $\mathrm{N}$ - and $\mathrm{C}$-terminal domains suggest that each holds unique functions and may help to develop TRIB-targeting drugs with low cross-reactivity, but these domains have not been studied intensively.

The N- and C-terminal domains of TRIB3 are unstructured domains for which a $3 \mathrm{D}$ conformation cannot be predicted based on the amino acid sequence, as shown in Figure 2A [7]. In order to understand the contribution of the different domains of TRIB3 ( $\mathrm{N}$ - and $\mathrm{C}$-terminus and pseudokinase domain) to its interactome and to gain an insight into how these interactions take place, we generated TRIB3 mutants lacking the N-terminal domain (amino acids 1-69, TRIB3- $\Delta \mathrm{N}$-terminal) and the C-terminal domain (amino acids 316-358, TRIB3-C-terminal) and performed an AP-MS experiment, as described above (Figure 2B). A summary of the top 25 interactions of the $\mathrm{C}$-terminal and $\mathrm{N}$-terminal domains is shown in Table 4. In agreement with previous studies [45], the interaction with COP1 and DET1 requires the presence of the $\mathrm{C}$-terminal domain, as binding is lost with the TRIB3- $\Delta C$ mutant (Figure 2C). Moreover, novel proteins related to the ubiquitin degradation system were also found binding to the C-terminal domain of TRIB3, such as UBR2, an E3 ubiquitinprotein ligase that controls cell growth via mTOR signaling [48]. These findings confirm the concept that the C-terminal domain is required for TRIB3 to act as a degradation platform. In addition to the E3 ubiquitin ligases we also identified USP16, a deubiquitinating enzyme that plays an important role in mitosis [49], suggesting a role for TRIB3 in this process as well. In addition, STK40 and DOCK11 were also found to interact through the C-terminal domain of TRIB3. This reinforces the notion that Tribbles proteins and the Tribbles-like protein STK40 can form the homo/hetero dimers mentioned above. DOCK11 is a guanine nucleotide-exchange factor that activates CDC42 and RAC1 [50]; the biological relevance of this interaction remains to be established.

Table 4. Top binding partners of TRIB3 $\Delta \mathrm{N}$ - and $\Delta \mathrm{C}$-Terminal domains based on $p$-value.

\begin{tabular}{|c|c|c|c|c|}
\hline Gene Name & -Log ( $p$-Value) & Adjusted $p$-Value & Log2 Fold Change * & Full Name \\
\hline \multicolumn{5}{|c|}{ TRIB3- $\Delta$ C-Terminal Binding partners } \\
\hline RFWD2 & 4.4826 & $4.54 \times 10^{-6}$ & 5.943 & COP1 E3 Ubiquitin Ligase \\
\hline STK40 & 3.1119 & 0.0002 & 6.370 & Serine/Threonine Kinase 40 \\
\hline DOCK11 & 3.7967 & 0.004 & 3.498 & Dedicator of Cytokinases 11 \\
\hline DET1 & 3.8995 & $1.02 \times 10^{-5}$ & 4.667 & DET 1 Partner of COP1 E3 Ubiquitin Ligase \\
\hline USP16 & 2.5863 & 0.01 & 3.822 & Ubiquitin Specific Peptidase 16 \\
\hline UBR2 & 3.1640 & 0.001 & 2.610 & $\begin{array}{l}\text { Ubiquitin Protein Ligase E3 } \\
\text { Component N-Recognin } 2\end{array}$ \\
\hline DDI2 & 1.8154 & 0.02 & 1.811 & DNA Damage 1 Homolog 2 \\
\hline \multicolumn{5}{|c|}{ TRIB3- $\Delta$ N-Terminal Binding partners } \\
\hline MKNK2 & 6.0395 & 0.007 & 3.525 & MAPK Interacting Serine/Threonine Kinase 2 \\
\hline WDR5 & 5.7443 & $4.38 \times 10^{-7}$ & 7.841 & WD Repeat Domain 5 \\
\hline COPS8 & 5.6291 & 0.01 & 3.123 & COP9 Signalosome Subunit 8 \\
\hline TP53 & 5.3723 & $3.16 \times 10^{-6}$ & 2.800 & Tumor Protein P53 \\
\hline PARN & 5.0650 & $4.38 \times 10^{-7}$ & 6.298 & Poly(A)-Specific Ribonuclease \\
\hline GEN1 & 4.8329 & $1.35 \times 10^{-5}$ & 4.438 & Gen1 Holliday Junction 5' Flap Endonuclease \\
\hline SPEN & 3.8986 & $3.87 \times 10^{-6}$ & 4.154 & SPEN Family Transcriptional Repressor \\
\hline
\end{tabular}


Table 4. Cont.

\begin{tabular}{ccccc}
\hline Gene Name & -Log $(p$-Value $)$ & Adjusted $p$-Value & Log2 Fold Change & Full Name \\
\hline ZNFP24 & 3.8823 & 0.0001 & 1.719 & Zinc Finger Protein 91 \\
\hline NACC1 & 3.7582 & $3.08 \times 10^{-5}$ & 2.193 & Nucleus Accumbens Associated 1 \\
\hline ZBTB1 & 3.5994 & $8.91 \times 10^{-5}$ & 4.004 & Zinc Finger And BTB Domain 1 \\
\hline SETD2 & 3.5315 & 0.002 & 1.627 & $\begin{array}{c}\text { SET Domain 2 Histone } \\
\text { Lysine Methyltranferase }\end{array}$ \\
\hline DPY30 & 3.4148 & $5.56 \times 10^{-5}$ & 2.296 & Dpy-30 Histone Methyltranferase \\
\hline CBBP5 & 3.2480 & 0.0009 & 4.471 & RB Binding Protein 5 \\
\hline MYC & 2.6206 & 0.01 & 2.233 & MYC Proto-Oncogene \\
\hline EP300 & 2.5832 & 0.005 & 4.017 & E1A Binding Protein P300 \\
\hline MKNK1 & 2.5381 & 0.05 & 3.411 & MAPK Interacting Serine/Threonine Kinase 1 \\
\hline ASH2L & 2.4872 & 0.001 & 5.577 & Set1/Ash2 Histone Methyltranferase \\
Complex Subunit
\end{tabular}

* Absolute Log 2-fold change calculated using mean intensity of $\Delta \mathrm{N}$-Terminal condition compared to $\Delta \mathrm{C}$-Terminal condition.

The N-terminal domain of TRIB3 contains a nuclear localization signal sequence that directs TRIB3 towards the nucleus and a PEST domain that might affect TRIB3 stability. The interactors that were lost when deleting the N-terminus included several transcription factors and regulators, which are mainly found in the nucleus, such as ZBTB1, p300, and SPEN (Figure 2C). The interaction between TRIB3 and ZBTB1 was confirmed by co-immunoprecipitation assays (Figure $2 \mathrm{D}$ and File S2). In addition, we found all the subunits of the WRAD complex (WDR5, DPY30, ASH2L and RbBP5) binding to the Nterminus of TRIB3. The WRAD complex is crucial for SET1 histone methyl transferases to catalyze histone 3 lysine 4 methylation [51]. The interactions between TRIB3 and WRAD complex components were also confirmed by co-immunoprecipitation experiments (to be published elsewhere).

Interestingly we also found the interaction with serine/threonine protein kinase D1 (PRKD1), and the MAPK interacting serine/threonine kinase 1 and 2 (MKNK1 and MKNK2) suggesting that the regulation of mitogen-activated protein kinase (MAPK) signaling does not happen only through the C-terminal [10] and pseudokinase domains [31] as reported earlier but also through the $\mathrm{N}$-terminal domain. It is also worth mentioning the interactions with TP53 and COPS8. TP53, the so-called "guardian of the genome", is the most common tumor suppressor that is found mutated across all cancer types [52] and it regulates the cell cycle, as well as the apoptosis of damaged cells. COPS8 is a component of the COP9 signalosome that is involved in the phosphorylation of p53 [53].

Taken together, these data indicate that TRIB3 is a putative important transcriptional regulator and this role is carried out mainly through the N-terminal domain. In contrast, the C-terminal domain of TRIB3 is required for the interaction with components of the ubiquitin system and for the formation of homo/hetero dimers. 


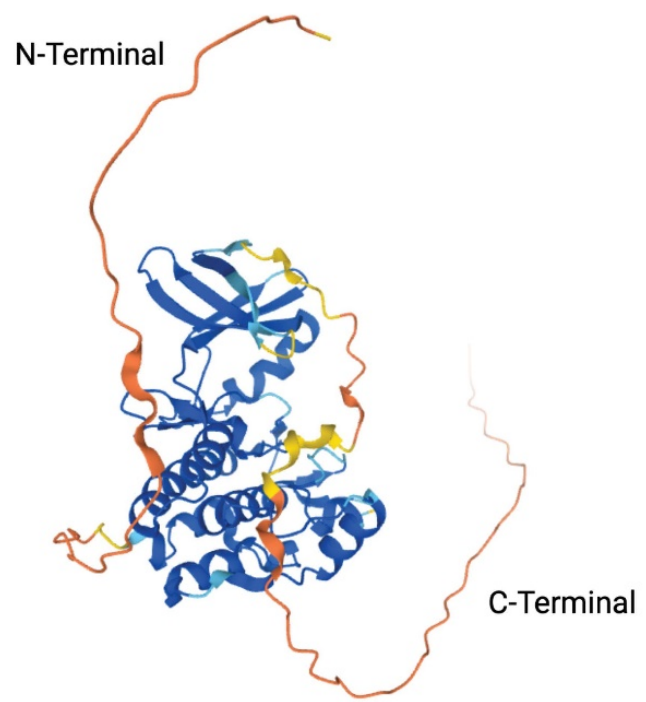

\begin{tabular}{|c|c|c|}
\hline \multirow{2}{*}{$\frac{6}{\mathrm{~N}-\mathrm{Ter}}$} & \multicolumn{2}{|c|}{316} \\
\hline & PKD & C-Ter \\
\hline & PKD & C-Ter \\
\hline N-Ter & PKD & \\
\hline
\end{tabular}

WT

$\Delta \mathrm{N}$-Terminal

$\Delta$ C-Terminal

\section{Interactors}

\begin{tabular}{|ll|}
\hline \multicolumn{2}{|c|}{ N-Terminal } \\
\hline \hline PARN & GEN1 \\
WDR5 & PRKD1 \\
ASHL2 & MKNK2 \\
RBBP5 & MKNK1 \\
EP300 & NACC1 \\
ZBTB1 & SPEN \\
TP53 & COPS8 \\
\hline
\end{tabular}

\begin{tabular}{|l|}
\hline \multicolumn{1}{|c|}{ C-Terminal } \\
\hline \hline COP1 \\
DET1 \\
STK40 \\
DOCK11 \\
USP16 \\
UBR2 \\
\hline
\end{tabular}

C

TRIB3 $\Delta C$-Terminal vs TRIB3 $\Delta \mathrm{N}$-Terminal

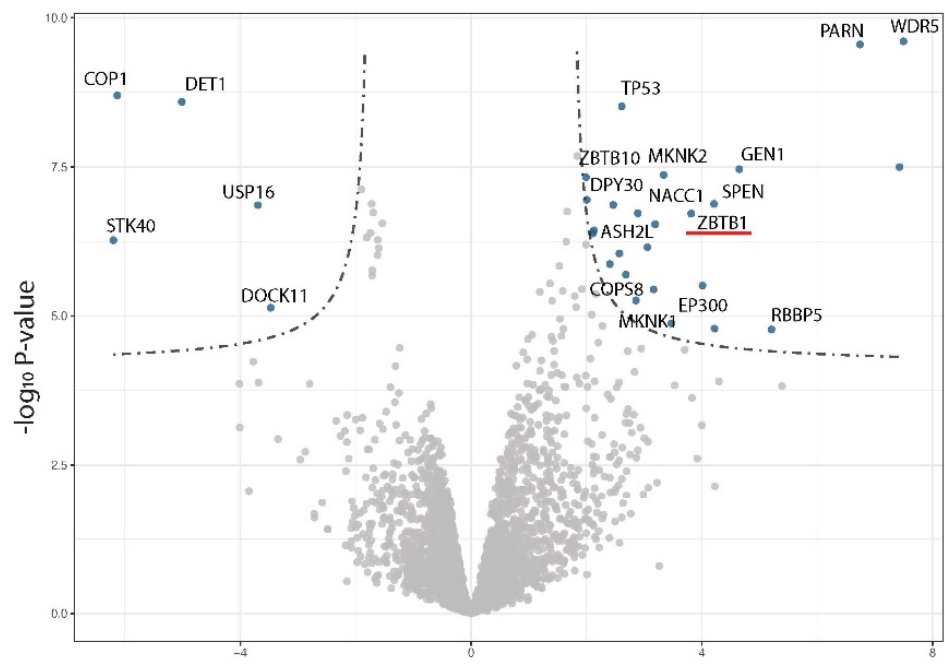

$\log _{2}$ fold change

E
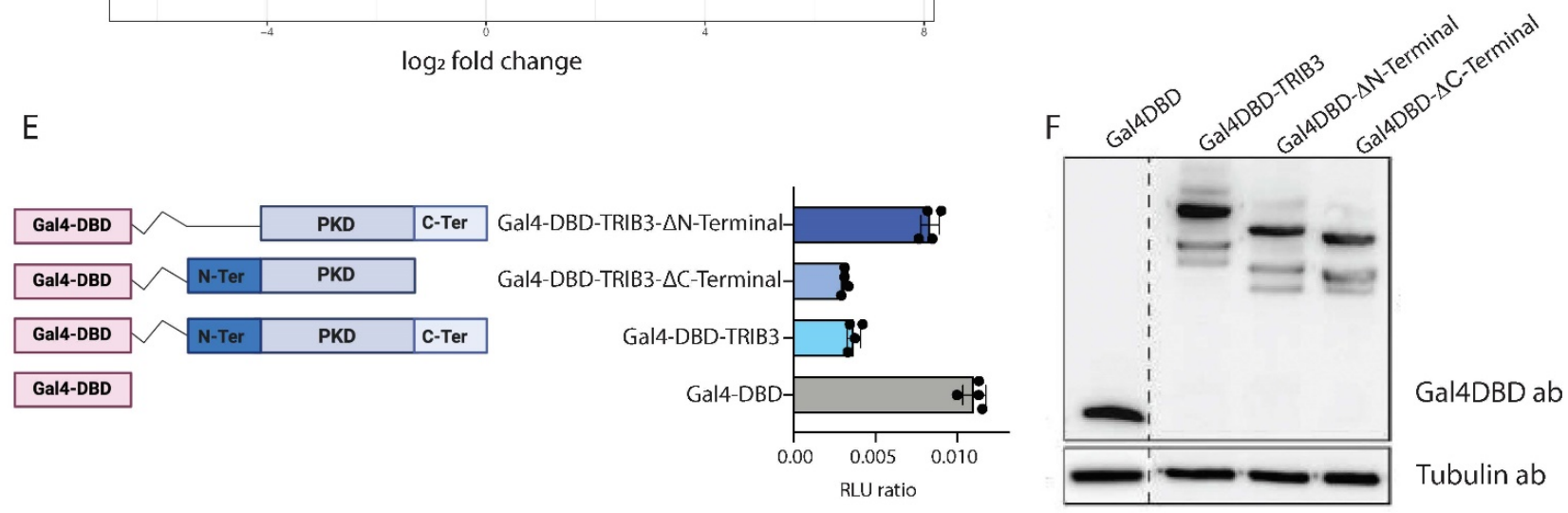

D

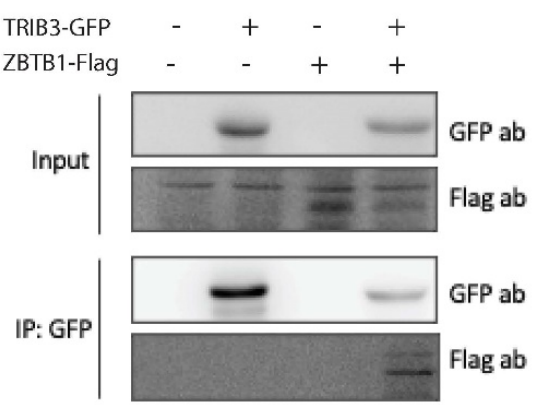

Figure 2. Contribution of TRIB3 domains to its interactome and function. (A) Human TRIB3 structure prediction by AlphaFold. Colors represent pLDDT score (blue: very high confidence, light blue: confident, yellow: low and orange: very low or unstructured). (B) Schematic representation of TRIB3 mutants and specific interactors lost when the indicated domain was removed. (C) Volcano plot showing interaction of the N-terminal and C-terminal domains of TRIB3 in HEK293T cells. (D) Co-immunoprecipitation assay of TRIB3-GFP and ZBTB1-Flag in HEK293T cells. (E) Gal4 reporter assay of Gal4-DBD, Gal4-TRIB3, Gal4-TRIB3- $\Delta$ N-terminal and Gal4-TRIB3- $\Delta$ C-terminal in Hek293T cells. Data is normalized using Renilla luciferase. (F) Western blot using Gal4DBD and tubulin antibodies showing similar expression of the constructs used for the Gal4 reporter assay. 


\subsection{TRIB3 Function as a Transcriptional Repressor}

While our data revealed an interaction between the N-terminus of TRIB3 and for example SET1 histone methyl transferase complexes and p300, which are associated with transcriptional activation [51,54], the same TRIB3 domain also interacted with various proteins that are involved in transcriptional repression, such as ZBTB1 and SPEN $[55,56]$. In addition, TRIM28 (also known as KAP-1 or TIF1 $\beta$ ) and SETDB1, proteins that may form a repressor complex with ZBTB1 $[57,58]$ (were also detected (adjusted $p$-value $\leq 0.05$. Data not shown).

To assess the effect of TRIB3 on transcription, we fused TRIB3 to the DNA binding domain of Gal4 (Gal4DBD) and tested the transcriptional activity of the fusion protein on a reporter plasmid with high basal activity(5xGal4-TK-Luc) [36]. As shown in Figure 2E, TRIB3 had a repressive effect when compared to the Gal4DBD alone, similar to for example GalDBD fusions of ZBTB1 and TRIM28 [59,60]. This TRIB3-mediated repression was mostly lost when the N-terminus was deleted, but the TRIB3 $\Delta$ C-terminal mutant retained repressor activity (Figure 2E). These results are in line with the mass spectrometry data, described above, in which we found that a high number of transcriptional repressors are able to bind through the N-terminal of TRIB3. Gal4DBD fusion proteins were expressed at similar levels, excluding the possibility that differences in activity were due to expression differences (Figure 2F and File S2). We conclude, therefore, that the N-terminus of TRIB3 harbours repressive activity when tethered to the DNA, which may be due to repressor proteins, such as ZBTB1 (and its associated proteins TRIM28 and SETDB1) and SPEN binding specifically to this region of the protein. Furthermore, while the N-terminus of Tribbles has the ability to recruit both transcriptional activators (e.g., MLL complex) and repressors (e.g., ZBTB1 and SPEN), the balance appears to be in favor of transcriptional repression, at least in this experimental setting.

\subsection{Comparison of TRIB1 and TRIB3 Interactomes in MCF7 Cells}

Having developed a robust AP-MS workflow to identify the interaction partners of Tribbles proteins, we wished to address the different roles of TRIB1 and TRIB3 in breast cancer, where high levels of both proteins have been reported to be associated with poor prognosis and lower survival rates [26,61,62]. For this we generated inducible TRIB1-tGFP and TRIB3-tGFP stable cell lines in the breast cancer cell line MCF7, a model for luminal A breast cancer, allowing immediate short-term overexpression of TRIB1 and -3 , as well as control over the amount of protein being overexpressed. A summary of the constructs used and the workflow followed to identify interacting proteins is depicted in Figure 3A. Expression of TRIB1-tGFP, TRIB3-tGFP and -tGFP was observed by Western blot after $24 \mathrm{~h}$ treatment with doxycycline and no expression was observed in untreated cells (Figure 3B and File S2). TRIB3 was predominantly-but not exclusively-localized in the nucleus as determined by confocal microscopy (Figure 3C). In contrast to the predominant nuclear localization of TRIB1 in HEK293T cells ([18] data not shown) TRIB1 was mainly localized in the cytoplasm in MCF7 cells (Figure 3C), supporting the view that subcellular localization of Tribbles depends on cellular context and conditions [17].

Importantly, long-term overexpression of TRIB3 was recently linked to increased proliferation in MCF7 cells [62], which potentially confounds interactome profiles, but no significant effects on cell proliferation were observed within the 24-h timeframe of our experiments (data not shown). A summary of top 20 interactors for TRIB1 and TRIB3 (Figure 3D) is listed in Table 5. Interactors common to both TRIB1 and TRIB3 included COP1 and CDKN1A. The first one is a common interactor of all Tribbles family members that has been widely studied and was also detected in the current study in HEK293T cells (Figure 1), and the second one is a cyclin-dependent kinase inhibitor that is tightly controlled by TP53 [63]. CDKN1A mediates G1 cell cycle arrest in response to a variety of external stimulus. Given the fact that Tribbles were originally described as a cell cycle regulators in Drosophila [64], this might be another mechanism by which these proteins regulate proliferation. In addition, both TRIB1 and TRIB3 also interacted with 
fatty acid synthetase (FASN), an enzyme that catalyzes the synthesis of palmitate from acetyl-CoA and malonyl-CoA. FASN overactivity has been implicated in cancer onset and progression in many cancers [65]. Interestingly, FASN has also been shown to be a transcriptional target for TRIB1 [66]. Among the specific TRIB1 interactors histone deacetylase 6 (HDAC6) stands out. HDAC6, which is mostly cytoplasmatic, has been implicated in cancer and metastasis formation in breast cancer [67]. As described above for HEK293T cells, TRIB3 interacted with a number of transcription factors that are mostly associated with transcriptional repression. The interaction with ZBTB1 was also detected in MCF7 cells among other zinc finger proteins (ZNF746, ZNF12, ZNF24) (Figure 3E), many of which are related to transcriptional repression [68]. In fact, ZBTB1 has been recently associated with resistance to tamoxifen and aerobic glycolysis in breast cancer cells [69]. Both resistance to drug treatment and glucose metabolism are major cellular pathways in which TRIB3 has been implicated before [70,71]; future studies are needed to establish whether the TRIB3-ZBTB1 interaction plays a role in these pathways. Similar to HEK293T cells, the interaction between TRIB3 and the TIM-TOM complex was also detected in MCF7 cells (Supplementary Figure S2), suggesting a mitochondrial pool and function for this protein. To further validate the role of TRIB3 as a transcriptional repressor we tested the Gal4DBD-TRIB3 fusion protein, as described above, for HEK293T cells, and also detected reduced transcriptional activity in these MCF7 breast cancer cells (Figure 3F). These findings indicate that our AP-MSMS approach provides a powerful tool to unravel novel pseudokinase biology, one that is not limited to a single cell system.

A

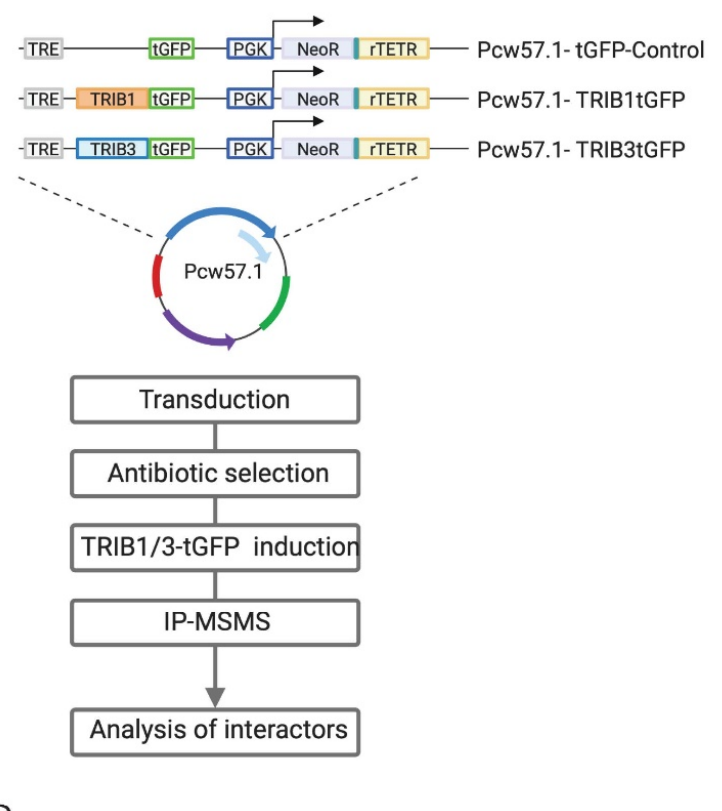

B

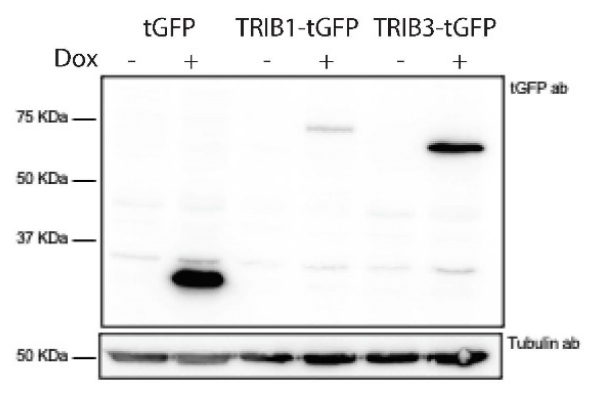

C

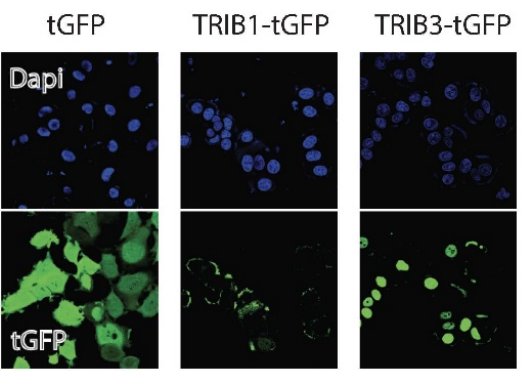

D
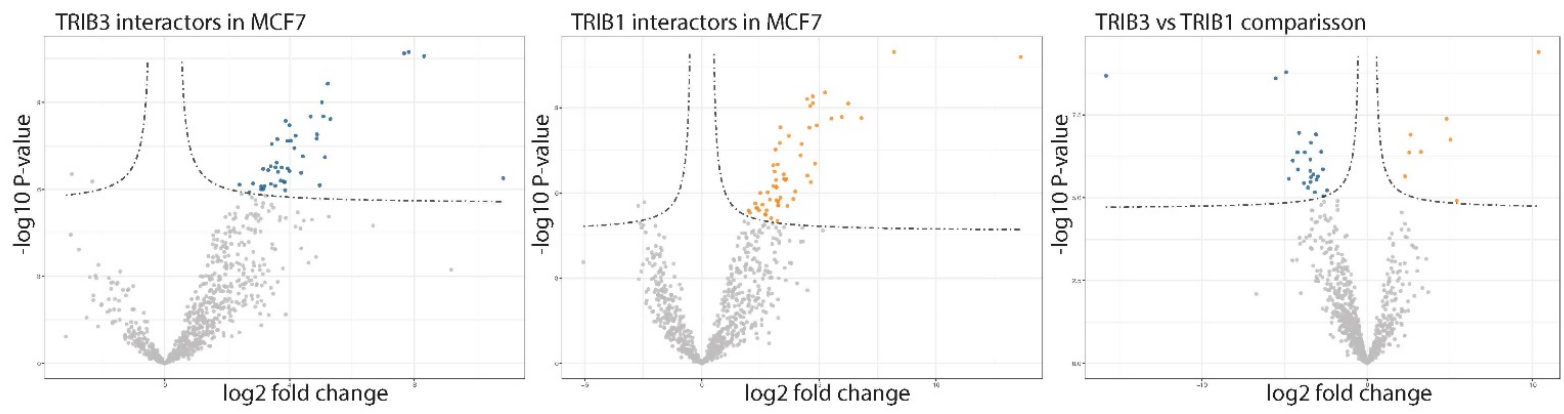

Figure 3. Cont. 
E

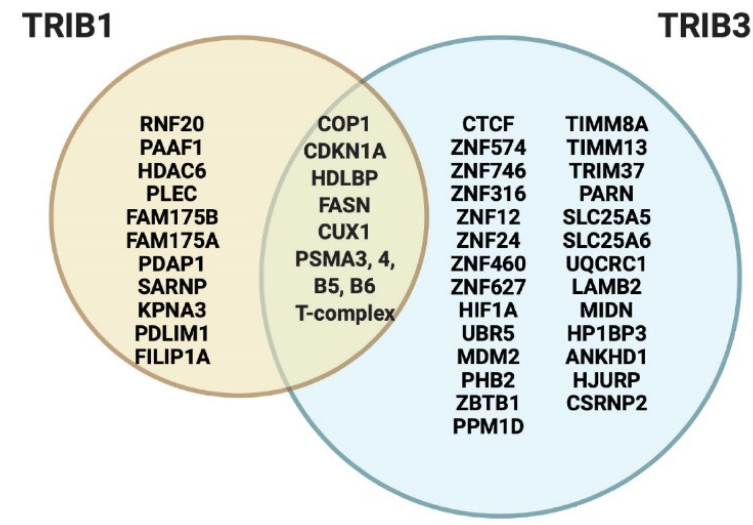

F

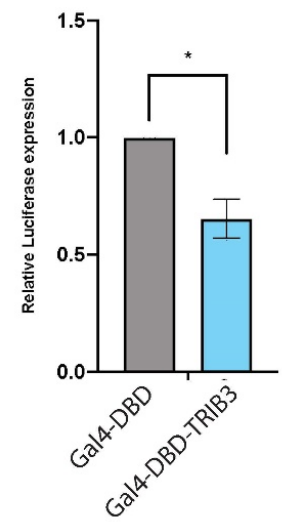

Figure 3. TRIB1 and TRIB3 interactors in MCF7 cells. (A) Schematic representation of inducible constructs and workflow of the AP-MS experiments followed in MCF7 cells. (B) Western blot using t-GFP antibody sowing inducible expression of TRIB1-tGFP and TRIB3-tGFP upon doxycycline treatment and Tubulin expression as loading control. (C) Confocal images taken at $40 \times$ magnification showing tGFP, TRIB1-tGFP and TRIB3-tGFP localization upon doxycycline induction. (D) Volcano plots of TRIB1 and TRIB3 interactors compared with tGFP control in MCF7 cells and a volcano plot showing the comparison between TRIB1 and TRIB3 interactome in these cells. (E) Venn diagram of similar and different interactors between TRIB1 and TRIB3 in MCF7 cells detected in the AP-MSMS experiments. (F) Gal4 reporter assay of Gal4-DBD and Gal4-TRIB3 in MCF7 cells. Data is normalized using Renilla luciferase. Data is indicated as mean \pm SEM. $p$-values were calculated using two-tailed Student's $t$-test $\left({ }^{*} p<0.05\right)$.

Table 5. Top 20 TRIB1 and TRIB3 binding partners in MCF7 cells based on $p$-value.

\begin{tabular}{|c|c|c|c|c|}
\hline Gene Name & $-\log (p$-Value) & Adjusted $p$-Value & Log2 Fold Change & Full Name \\
\hline \multicolumn{5}{|c|}{ TRIB1 binding partners in MCF7 } \\
\hline PFN1 & 6.8434 & 0.007 & 2.550 & Profilin 1 \\
\hline CDKN1A & 6.7563 & 0.0002 & 2.315 & Cyclin Dependent Kinase Inhibitor 1A \\
\hline CCT5 & 6.0523 & 0.0002 & 2.083 & T-complex protein 1 subunit epsilon \\
\hline PDAP1 & 6.0427 & 0.006 & 2.151 & PDGFA Associated Protein 1 \\
\hline$P R K D C$ & 5.8532 & 0.0001 & 2.508 & $\begin{array}{l}\text { DNA-dependent protein kinase } \\
\text { catalytic subunit }\end{array}$ \\
\hline$E R H$ & 5.8170 & $4.16 \times 10^{-5}$ & 3.553 & ERH MRNA Splicing and Mitosis Factor \\
\hline RFWD2 & 5.5455 & $1.08 \times 10^{-8}$ & 6.240 & COP1 E3 Ubiquitin Ligase \\
\hline RNF40 & 5.3754 & $7.73 \times 10^{-6}$ & 3.083 & E3 ubiquitin-protein ligase BRE1B \\
\hline FASN & 5.3652 & 0.01 & 1.708 & Fatty Acid Synthase \\
\hline MTHFD1 & 5.0852 & $4.23 \times 10^{-5}$ & 2.525 & C-1-tetrahydrofolate synthase \\
\hline STIP1 & 4.9889 & $2.89 \times 10^{-5}$ & 3.699 & Stress-induced-phosphoprotein 1 \\
\hline DNAJB1 & 4.9816 & $2.18 \times 10^{-7}$ & 5.567 & DnaJ Heat Shock Protein Family Member B1 \\
\hline STK40 & 4.9431 & $5.94 \times 10^{-6}$ & 5.105 & Serine/threonine Kinase 40 \\
\hline PLEC & 4.3460 & 0.0006 & 3.183 & Plectin \\
\hline HDAC6 & 4.1498 & 0.01 & 2.356 & Histone Deacetylase 6 \\
\hline PAAF1 & 3.9612 & 0.008 & 2.609 & Proteasomal ATPase Associated Factor 1 \\
\hline EDF1 & 3.8339 & $1.82 \times 10^{-5}$ & 3.326 & Endothelial Differentiation Related Factor 1 \\
\hline CUX1 & 3.7878 & 0.003 & 2.122 & Cut like Homeobox 1 \\
\hline PRDX2 & 3.7664 & 0.01 & 3.741 & Peroxiredoxin 2 \\
\hline СЕВРВ & 2.9757 & 0.01 & 1.223 & CCAAT Enhancer Binding Protein Beta \\
\hline
\end{tabular}


Table 5. Cont.

\begin{tabular}{|c|c|c|c|c|}
\hline Gene Name & -Log ( $p$-Value) & Adjusted $p$-Value & Log2 Fold Change & Full Name \\
\hline \multicolumn{5}{|c|}{ TRIB3 binding partners in MCF7 } \\
\hline CDKN1A & 7.7691 & 0.0001 & 2.752 & Cyclin Dependent Kinase Inhibitor 1A \\
\hline TRIM37 & 7.6337 & 0.01 & 3.405 & Tripartite Motif Containing 37 \\
\hline ZNF217 & 7.5252 & $2.35 \times 10^{-6}$ & 2.732 & Zinc Finger Protein 217 \\
\hline TRIB1 & 6.5117 & 0.001 & 2.966 & Tribbles Pseudokinase 1 \\
\hline HIF1A & 6.4611 & 0.0001 & 2.139 & Hypoxia Inducible Factor 1 Subunit Alpha \\
\hline PPM1D & 6.4143 & 0.006 & 2.567 & Protein Phosphatase Mg Dependent 1D \\
\hline ZBTB1 & 6.0395 & 0.01 & 1.828 & Zinc Finger And BTB Domain 1 \\
\hline СЕВРВ & 5.7224 & 0.0001 & 2.463 & CCAAT/enhancer-binding protein beta \\
\hline WDR5 & 5.7100 & 0.001 & 2.372 & WD repeat-containing protein 5 \\
\hline ZNF627 & 5.3262 & 0.003 & 2.866 & Zinc Finger Protein 627 \\
\hline ZNF460 & 5.1982 & 0.002 & 1.775 & Zinc Finger Protein 460 \\
\hline$D N A J B 1$ & 5.1152 & $2.35 \times 10^{-6}$ & 4.064 & DnaJ homolog subfamily B member 1 \\
\hline PARN & 4.9613 & $2.48 \times 10^{-5}$ & 3.301 & Poly(A)-specific Ribonuclease \\
\hline RFWD2 & 4.9105 & $5.62 \times 10^{-7}$ & 3.904 & COP1 E3 Ubiquitin Ligase \\
\hline FASN & 4.6569 & 0.05 & 1.709 & Fatty Acid Synthase \\
\hline TIMM13 & 3.8986 & $1.92 \times 10^{-5}$ & 2.370 & $\begin{array}{l}\text { Translocase of Inner Mitochondrial } \\
\text { Membrane } 13\end{array}$ \\
\hline ZNF12 & 3.7582 & 0.01 & 2.602 & Zinc Finger Protein 12 \\
\hline$K D M 3 B$ & 3.5315 & 0.05 & 2.185 & Lysine-specific demethylase 3B \\
\hline DPY30 & 3.3126 & 0.001 & 2.089 & Dpy-30 Histone Methyltranferase Complex \\
\hline TP53 & 2.3725 & 0.0001 & 2.372 & Cellular tumor antigen p53 \\
\hline
\end{tabular}

* Absolute log 2-fold change calculated using mean intensity of TRIB3 condition compared to TRIB1 condition.

\section{Discussion}

Pseudokinases, such as the three human TRIB proteins, hold promise as biomarkers in cancer, but their molecular functions are still incompletely understood. Here we reported a systematic characterization of TRIB1, -2 and -3 interactomes in HEK 293T cells to provide a better understanding of the differences and redundancies in Tribbles' functions. In addition, our mass spectrometry-based approach revealed the importance of the intrinsically disordered N-Terminal domain of TRIB3 in the interaction with transcriptional regulatory proteins. We showed that TRIB3 is associated with transcriptional repression and that this role is mostly carried by the N-Terminal of TRIB3. Moreover, we discover new interactors of TRIB1 and -3 in breast cancer cells that might help to understand the role of these proteins in cancer pathophysiology.

The study of the function of pseudoenzymes presents obvious difficulties in comparison with their enzymatically active counter partners, as no catalytic product can be measured as a read-out of their activity. Most of these pseudoenzymes rely on proteinprotein interactions (PPI) to exert their function and several mass spectrometry-based techniques can be used for the identification of interactors, such as proximity ligation or crosslinking mass spectrometry, all with particular advantages and disadvantages [32]. Our data shows how powerful is the use of AP-MS approaches for the discovery of new interactors and the study of pseudoenzyme function. Modern mass spectrometers have a tremendous sensitivity that allows them to detect the smallest contaminant and, therefore, a quantitative filter must be introduced to differentiate between genuine interactors and background noise. These quantitative filters can be introduced in the form of isotopes 
or in the form of algorithms for label-free quantification; an example of the last is the intensity-based absolute quantification (iBAQ) used in this study, which allowed us to determine protein abundance. Taken together, this shows that quantitative MS-based proteomics is the most powerful method for identifying PPI and studying pseudoenzyme function to date.

Through AP-MS we confirmed previously reported Tribbles-interacting proteins and identified novel partners. As demonstrated before, we show that all three human tribbles family members can interact with the E3 ubiquitin ligase COP1. However, it seems that TRIB1 function is more dominated by the interaction with COP1, and that explains the high amount of proteasomal regulatory proteins as well as the low abundance of other interactors. TRIB2 and -3 also interact with COP1 but, next to these, many other interactors, not related to proteasomal degradation, were detected. This also seems the case when we compared the interactomes of TRIB1 and -3 in breast cancer cells. Moreover, TRIB1 protein expression was lower when compared to TRIB3 upon induction with doxycycline (Figure 3B), and, thus, could be reverted when proteasomal degradation was inhibited (data not shown), indicating that the lower amount of TRIB1 protein was the result of proteasomal degradation and was not due to different responses to doxycycline induction. TRIB1 subcellular localization appeared to be mostly cytoplasmatic in comparison with TRIB3, which showed predominant nuclear localization; this can also explain the difference in protein stability and interactomes. In addition, our data also demonstrates some interactions that had been suggested in literature before but not experimentally demonstrated, such as the interaction with p53 or the interaction with CDKN1 [72,73]. These interactions might be related to the ability of Tribbles to regulate the cell cycle and therefore the implications for cancer research are potentially very important. Both of these proteins are among the most commonly found mutated across all cancer types [74,75]. These interactions, together with others described above, might suggest a role of Tribbles in DNA damage. Furthermore, whether for example the TRIB3-CDKN1 interaction contributes to the increased proliferation observed upon long-term overexpression of TRIB3 in MCF7 cells [62] remains to be established.

Finally, we report many novel interacting proteins that interact with one or more Tribbles family members. Amongst the cellular proteins with well-established functions is the metabolic enzyme FASN. Interestingly, FASN is a major regulator of neoplastic lipogenesis and is commonly found overexpressed in many cancers [65], is a metabolic oncogene that has been suggested as an attractive target for cancer therapy [76] and, given the ability of TRIB1 and -3 to mark proteins for proteasomal degradation, this interaction represents a promising therapeutic approach for breast cancer. The class of well-characterized TRIB3 interacting proteins also includes the transcriptional repressors ZBTB1 and SPEN, which may be responsible for the transcriptional repression observed when TRIB3 is tethered to DNA. The ability of tribbles to regulate the functions of transcription factors has been reported before [29-31]; however, their role as a transcriptional repressor has not been shown before. While novel Tribbles interacting proteins with well-characterized functions may present immediate new entries for future research, interacting proteins with poorly understood functions such as the zinc finger proteins found interacting with TRIB3, obviously will need more characterization before their value - be it therapeutic or more fundamental — can be assessed. It should be noted that the protein kinase AKT/PKB, a previously described interaction partner of TRIB3 [14], was detected in the TRIB1 interactome but was not a dominant hit in the TRIB3 interactomes in either HEK293T or MCF7 cells. Furthermore, when we compared the TRIB3 interactomes between the genetic variants R84 and Q84harboring an arginine and glutamine residue at position 84, respectively-no significant differences in interactomes were found (data not shown). The $\mathrm{R}$ variant was reported to be a more potent inhibitor of insulin signaling through stronger AKT binding when tested in hepatocytes [77]. Together, these findings support the view that TRIB interactomes may harbor a uniform component (overlap between for example HEK293T cells and MCF7 cells) as well as a flexible component that depends on cell type (e.g., hepatocyte vs. HEK293T 
cells vs. MCF7 breast cancer cells) or cellular status (e.g., proliferative status, metabolic status). Analyzing and comparing TRIB interactomes in more cell types and under different conditions is, therefore, an important future direction.

In summary, we have shown new interactions that might be very relevant for cancer therapy and could situate Tribbles as therapeutic targets in breast cancer and we have shown how powerful and useful is the study of tribbles' functions through MS-based proteomics approaches.

\section{Conclusions}

We have used an MS-based approach to find new interactors of Tribbles proteins that might serve as starting point for future research. We have shown the ability of TRIB3 to function as a transcriptional repressor as we looked at the similarities and differences between TRIB1 and -3 in breast cancer cells, finding new interactors that might help to understand better the function of these proteins in breast cancer pathology.

Supplementary Materials: The following are available online at https:/ / www.mdpi.com/article/10 .3390 / cancers13246318/s1, Figure S1: Comparison of human TRIB1/2 and 3 protein sequence using Clustal Omega software. Figure S2: Comparison of TRIB1 and TRIB3 interactors in HEK293T and MCF7 cells. File S1: TRAIN Consortium members, File S2: Original Western blot figures.

Author Contributions: Conceptualization, M.H.-Q., E.K.-T., H.V., E.K.; methodology, M.H.-Q., R.B., A.B., S.d.H., P.S.A., R.v.E., H.V.; validation, M.H.-Q., R.B., A.B., S.d.H., P.S.A.; formal analysis, M.H.-Q., R.B., A.B., S.d.H., P.S.A.; investigation, M.H.-Q., R.B., A.B., S.d.H., P.S.A., R.v.E., E.K.-T., H.V., E.K.; Data curation, P.S.A., H.V.; writing-original draft preparation, M.H.-Q.; writing-review and editing, M.H.-Q., E.K.-T., H.V., E.K.; supervision, E.K.-T., H.V., E.K.; wisualisation, M.H.-Q., P.S.A.; funding acquisition, E.K.-T., E.K. All authors have read and agreed to the published version of the manuscript.

Funding: This study was supported by a grant from the European Union's Horizon 2020 Marie Skłodowska-Curie Innovative Training Network, TRAIN (project no. 721532), the X-omics initiative funded by NWO (project 184.034.019) and a combined Diabetes Breakthrough grant from the Dutch Diabetes Research Foundation and the Netherlands Organisation for Health Research and Development (ZonMW; project no. 459001006).

Institutional Review Board Statement: Not applicable.

Informed Consent Statement: Not applicable.

Data Availability Statement: Data are available via ProteomeXchange with identifier PXD030404.

Acknowledgments: We thank S.W.C van Mil for plasmids. We also thank members of the Marie Skłodowska-Curie Innovative Training Network TRAIN (see Supplementary File S1 and A.C.O. Vertegaal (LUMC) and members of the Kalkhoven and van Mil laboratories (both UMC Utrecht) for helpful discussions.

Conflicts of Interest: The authors declare no conflict of interest.

\section{References}

1. Fabbro, D.; Cowan-Jacob, S.W.; Moebitz, H. Ten things you should know about protein kinases: IUPHAR Review 14 . Br. J. Pharmacol. 2015, 172, 2675-2700. [CrossRef]

2. Cohen, P.; Cross, D.; Jänne, P.A. Kinase drug discovery 20 years after imatinib: Progress and future directions. Nat. Rev. Drug Discov. 2021, 20, 551-569. [CrossRef]

3. Byrne, D.P.; Foulkes, D.M.; Eyers, P.A. Pseudokinases: Update on their functions and evaluation as new drug targets. Future Med. Chem. 2017, 9, 245-265. [CrossRef]

4. Richmond, L.; Keeshan, K. Pseudokinases: A tribble-edged sword. FEBS J. 2020, 287, 4170-4182. [CrossRef]

5. Eyers, P.A.; Keeshan, K.; Kannan, N. Tribbles in the 21st Century: The Evolving Roles of Tribbles Pseudokinases in Biology and Disease. Trends Cell Biol. 2017, 27, 284-298. [CrossRef] [PubMed]

6. Kiss-Toth, E.; Velasco, G.; Pear, W.S. Tribbles at the cross-roads. Biochem. Soc. Trans. 2015, 43, 1049-1050. [CrossRef]

7. Soubeyrand, S.; Martinuk, A.; Lau, P.; McPherson, R. TRIB1 Is Regulated Post-Transcriptionally by Proteasomal and NonProteasomal Pathways. PLoS ONE 2016, 11, e0152346. [CrossRef] [PubMed] 
8. Wang, J.; Zhang, Y.; Weng, W.; Qiao, Y.; Ma, L.; Xiao, W.; Yu, Y.; Pan, Q.; Sun, F. Impaired phosphorylation and ubiquitination by p70 S6 kinase (p70S6K) and Smad ubiquitination regulatory factor 1 (Smurf1) promote tribbles homolog 2 (TRIB2) stability and carcinogenic property in liver cancer. J. Biol. Chem. 2013, 288, 33667-33681. [CrossRef]

9. Murphy, J.; Nakatani, Y.; Jamieson, S.A.; Dai, W.; Lucet, I.S.; Mace, P.D. Molecular Mechanism of CCAAT-Enhancer Binding Protein Recruitment by the TRIB1 Pseudokinase. Structure 2015, 23, 2111-2121. [CrossRef]

10. Yokoyama, T.; Kanno, Y.; Yamazaki, Y.; Takahara, T.; Miyata, S.; Nakamura, T. Trib1 links the MEK1/ERK pathway in myeloid leukemogenesis. Blood 2010, 116, 2768-2775. [CrossRef]

11. Durzynska, I.; Xu, X.; Adelmant, G.; Ficarro, S.B.; Marto, J.A.; Sliz, P.; Uljon, S.; Blacklow, S.C. STK40 Is a Pseudokinase that Binds the E3 Ubiquitin Ligase COP1. Structure 2017, 25, 287-294. [CrossRef]

12. Yu, H.; He, K.; Wang, L.; Hu, J.; Gu, J.; Zhou, C.; Lu, R.; Jin, Y. Stk40 represses adipogenesis through translational control of CCAAT/enhancer-binding proteins. J. Cell Sci. 2015, 128, 2881-2890. [CrossRef] [PubMed]

13. Yokoyama, T.; Nakamura, T. Tribbles in disease: Signaling pathways important for cellular function and neoplastic transformation. Cancer Sci. 2011, 102, 1115-1122. [CrossRef]

14. Das, R.; Sebo, Z.; Pence, L.; Dobens, L.L. Drosophila tribbles antagonizes insulin signaling-mediated growth and metabolism via interactions with Akt kinase. PLoS ONE 2014, 9, e109530. [CrossRef] [PubMed]

15. Xiang, D.; Zhu, X.; Zhang, Y.; Zou, J.; Li, J.; Kong, L.; Zhang, H. Tribbles homolog 2 promotes hepatic fibrosis and hepatocarcinogenesis through phosphatase 1A-Mediated stabilization of yes-associated protein. Liver Int. 2021, 41, 1131-1147. [CrossRef]

16. Ferreira, B.I.; Santos, B.; Link, W.; De Sousa-Coelho, A.L. Tribbles pseudokinases in colorectal cancer. Cancers 2021, 13, 2825. [CrossRef]

17. Dobens, L.L.; Bouyain, S. Developmental roles of tribbles protein family members. Dev. Dyn. 2012, 241, 1239-1248. [CrossRef]

18. Kung, J.E.; Jura, N. The pseudokinase TRIB 1 toggles an intramolecular switch to regulate COP 1 nuclear export. EMBO J. 2019, 38, e99708. [CrossRef]

19. Yu, J.-J.; Zhou, D.-D.; Yang, X.-X.; Cui, B.; Tan, F.-W.; Wang, J.; Li, K.; Shang, S.; Zhang, C.; Lv, X.-X.; et al. TRIB3-EGFR interaction promotes lung cancer progression and defines a therapeutic target. Nat. Commun. 2020, 11, 3660. [CrossRef]

20. Shahrouzi, P.; Astobiza, I.; Cortazar, A.R.; Torrano, V.; Macchia, A.; Flores, J.M.; Niespolo, C.; Mendizabal, I.; Caloto, R.; Ercilla, A.; et al. Genomic and Functional Regulation of TRIB1 Contributes to Prostate Cancer Pathogenesis. Cancers 2020, $12,2593$. [CrossRef] [PubMed]

21. Kim, T.; Johnston, J.; Felipe, F.J.C.; Hamby, S.; Castillo-Lluva, S.; Consortium, T.C.; Goodall, A.H.; Velasco, G.; Ocana, A.; Muthana, M.; et al. TRIB1 regulates tumour growth via controlling tumour-associated macrophage phenotypes and is associated with breast cancer survival and treatment response. bioRxiv 2021. [CrossRef]

22. Stefanovska, B.; André, F.; Fromigué, O. Tribbles Pseudokinase 3 Regulation and Contribution to Cancer. Cancers 2021, $13,1822$. [CrossRef]

23. Ashton-Chess, J.; Giral, M.; Mengel, M.; Renaudin, K.; Foucher, Y.; Gwinner, W.; Braud, C.; Dugast, E.; Quillard, T.; Thebault, P.; et al. Tribbles-1 as a novel biomarker of chronic antibody-mediated rejection. J. Am. Soc. Nephrol. 2008, 19, 1116-1127. [CrossRef] [PubMed]

24. Lin, Z.-Y.; Huang, Y.-Q.; Zhang, Y.-Q.; Han, Z.-D.; He, H.-C.; Ling, X.-H.; Fu, X.; Dai, Q.-S.; Cai, C.; Chen, J.-H.; et al. MicroRNA224 inhibits progression of human prostate cancer by downregulating TRIB1. Int. J. Cancer 2014, 135, 541-550. [CrossRef] [PubMed]

25. Tang, B.; Wu, W.; Zhang, Q.; Sun, Y.; Cui, Y.; Wu, F.; Wei, X.; Qi, G.; Liang, X.; Tang, F.; et al. Inhibition of tribbles protein-1 attenuates radioresistance in human glioma cells. Sci. Rep. 2015, 5, 15961. [CrossRef]

26. Gendelman, R.; Xing, H.; Mirzoeva, O.K.; Sarde, P.; Curtis, C.; Feiler, H.S.; McDonagh, P.; Gray, J.W.; Khalil, I.; Korn, W.M. Bayesian network inference modeling identifies TRIB1 as a novel regulator of cell-cycle progression and survival in cancer cells. Cancer Res. 2017, 77, 1575-1585. [CrossRef]

27. Grandinetti, K.B.; A Stevens, T.; Ha, S.; Salamone, R.J.; Walker, J.R.; Zhang, J.; Agarwalla, S.; Tenen, D.; Peters, E.C.; Reddy, A.V. Overexpression of TRIB2 in human lung cancers contributes to tumorigenesis through downregulation of $\mathrm{C} / \mathrm{EBP} \alpha$. Oncogene 2011, 30, 3328-3335. [CrossRef]

28. Hill, R.; Kalathur, R.K.R.; Colaço, L.; Brandão, R.; Ugurel, S.; Futschik, M.; Link, W. TRIB2 as a biomarker for diagnosis and progression of melanoma. Carcinogenesis 2015, 36, 469-477. [CrossRef]

29. Yu, J.-M.; Sun, W.; Wang, Z.-H.; Liang, X.; Hua, F.; Li, K.; Lv, X.-X.; Zhang, X.-W.; Liu, Y.-Y.; Yu, J.-J.; et al. TRIB3 supports breast cancer stemness by suppressing FOXO1 degradation and enhancing SOX2 transcription. Nat. Commun. 2019, 10, 5720. [CrossRef] [PubMed]

30. Hua, F.; Shang, S.; Yang, Y.W.; Zhang, H.Z.; Xu, T.L.; Yu, J.J.; Zhou, D.D.; Cui, B.; Li, K.; Lv, X.X.; et al. TRIB3 Interacts with $\beta$-Catenin and TCF4 to Increase Stem Cell Features of Colorectal Cancer Stem Cells and Tumorigenesis. Gastroenterology 2019, 156, 708.e15-721.e15. [CrossRef]

31. Guan, H.; Shuaib, A.; De Leon, D.D.; Angyal, A.; Salazar, M.; Velasco, G.; Holcombe, M.; Dower, S.K.; Kiss-Toth, E. Competition between members of the tribbles pseudokinase protein family shapes their interactions with mitogen activated protein kinase pathways. Sci. Rep. 2016, 6, 32667. [CrossRef] 
32. Smits, A.H.; Vermeulen, M. Characterizing Protein-Protein Interactions Using Mass Spectrometry: Challenges and Opportunities. Trends Biotechnol. 2016, 34, 825-834. [CrossRef]

33. Smits, A.H.; Vermeulen, M. Quantitative liver proteomics identifies FGF19 targets that couple metabolism and proliferation. PLoS ONE 2017, 12, e0171185. [CrossRef]

34. Yuan, R.; Vos, H.; Van Es, R.M.; Chen, J.; Burgering, B.M.; Westendorp, B.; De Bruin, A. Chk1 and 14-3-3 proteins inhibit atypical E2Fs to prevent a permanent cell cycle arrest. EMBO J. 2018, 37, e97877. [CrossRef]

35. Van Nuland, R.; Smits, A.H.; Pallaki, P.; Jansen, P.W.T.C.; Vermeulen, M.; Timmers, H.T.M. Quantitative dissection and stoichiometry determination of the human SET1/MLL histone methyltransferase complexes. Mol. Cell. Biol. 2013, 33, $2067-2077$. [CrossRef]

36. Kalkhoven, E.; Teunissen, H.; Houweling, A.; Verrijzer, C.P.; Zantema, A. The PHD type zinc finger is an integral part of the CBP acetyltransferase domain. Mol. Cell. Biol. 2002, 22, 1961-1970. [CrossRef]

37. Jeninga, E.H.; Van Beekum, O.; van Dijk, A.-J.; Hamers, N.; Hendriks-Stegeman, B.I.; Bonvin, A.M.; Berger, R.; Kalkhoven, E. Impaired peroxisome proliferator-activated receptor gamma function through mutation of a conserved salt bridge (R425C) in familial partial lipodystrophy. Mol. Endocrinol. 2007, 21, 1049-1065. [CrossRef] [PubMed]

38. Baymaz, H.I.; Spruijt, C.G.; Vermeulen, M. Identifying Nuclear Protein-Protein Interactions Using GFP Affinity Purification and SILAC-Based Quantitative Mass Spectrometry. Methods Mol. Biol. 2014, 1188, 207-226. [CrossRef]

39. Yanagawa, Y.; Sullivan, J.A.; Komatsu, S.; Gusmaroli, G.; Suzuki, G.; Yin, J.; Ishibashi, T.; Saijo, Y.; Rubio, V.; Kimura, S.; et al. Arabidopsis COP10 forms a complex with DDB1 and DET1 in vivo and enhances the activity of ubiquitin conjugating enzymes. Genes Dev. 2004, 18, 2172-2181. [CrossRef] [PubMed]

40. Guruharsha, K.; Rual, J.-F.; Zhai, B.; Mintseris, J.; Vaidya, P.; Vaidya, N.; Beekman, C.; Wong, C.; Rhee, D.; Cenaj, O.; et al. A protein complex network of Drosophila melanogaster. Cell 2011, 147, 690-703. [CrossRef] [PubMed]

41. Jousse, C.; Deval, C.; Maurin, A.-C.; Parry, L.; Cherasse, Y.; Chaveroux, C.; Lefloch, R.; Lenormand, P.; Bruhat, A.; Fafournoux, P. TRB3 inhibits the transcriptional activation of stress-regulated genes by a negative feedback on the ATF4 pathway. J. Biol. Chem. 2007, 282, 15851-15861. [CrossRef]

42. Mayoral-Varo, V.; Jiménez, L.; Link, W. The critical role of trib2 in cancer and therapy resistance. Cancers 2021, 13, 2701. [CrossRef] [PubMed]

43. Hill, R.; Madureira, P.A.; Ferreira, B.; Baptista, I.; Machado, S.; Colaço, L.; dos Santos, M.; Liu, N.; Dopazo, A.; Ugurel, S.; et al. TRIB2 confers resistance to anti-cancer therapy by activating the serine/threonine protein kinase AKT. Nat. Commun. 2017, 8, 14687. [CrossRef]

44. Bauer, M.F.; Hofmann, S.; Neupert, W.; Brunner, M. Protein translocation into mitochondria: The role of TIM complexes. Trends Cell Biol. 2000, 10, 25-31. [CrossRef]

45. Jamieson, S.A.; Ruan, Z.; Burgess, A.E.; Curry, J.R.; McMillan, H.D.; Brewster, J.L.; Dunbier, A.K.; Axtman, A.D.; Kannan, N.; Mace, P.D. Substrate binding allosterically relieves autoinhibition of the pseudokinase TRIB1. Sci. Signal. 2018, 11, eaau0597. [CrossRef] [PubMed]

46. Al Dhaheri, N.; Wu, N.; Zhao, S.; Wu, Z.; Blank, R.D.; Zhang, J.; Raggio, C.; Halanski, M.; Shen, J.; Noonan, K.; et al. KIAA1217: A novel candidate gene associated with isolated and syndromic vertebral malformations. Am. J. Med. Genet. A 2020, 182, 1664-1672. [CrossRef] [PubMed]

47. Davuluri, G.; Song, P.; Liu, Z.; Wald, D.; Sakaguchi, T.F.; Green, M.R.; Devireddy, L. Inactivation of 3-hydroxybutyrate dehydrogenase 2 delays zebrafish erythroid maturation by conferring premature mitophagy. Proc. Natl. Acad. Sci. USA 2016, 113, E1460-E1469. [CrossRef]

48. Kume, K.; Iizumi, Y.; Shimada, M.; Ito, Y.; Kishi, T.; Yamaguchi, Y.; Handa, H. Role of N-end rule ubiquitin ligases UBR1 and UBR2 in regulating the leucine-mTOR signaling pathway. Genes Cells 2010, 15, 339-349. [CrossRef]

49. Zhuo, X.; Guo, X.; Zhang, X.; Jing, G.; Wang, Y.; Chen, Q.; Jiang, Q.; Liu, J.; Zhang, C. Usp16 regulates kinetochore localization of Plk1 to promote proper chromosome alignment in mitosis. J. Cell Biol. 2015, 210, 727-735. [CrossRef]

50. Lin, Q.; Yang, W.; Baird, D.; Feng, Q.; Cerione, R.A. Identification of a DOCK180-related guanine nucleotide exchange factor that is capable of mediating a positive feedback activation of Cdc42. J. Biol. Chem. 2006, 281, 35253-35262. [CrossRef]

51. Ali, A.; Tyagi, S. Diverse roles of WDR5-RbBP5-ASH2L-DPY30 (WRAD) complex in the functions of the SET1 histone methyltransferase family. J. Biosci. 2017, 42, 155-159. [CrossRef] [PubMed]

52. Bourdon, J.-C.; Surget, S.; Khoury, M.P. Uncovering the role of p53 splice variants in human malignancy: A clinical perspective. Oncol. Targets Ther. 2013, 7, 57-67. [CrossRef]

53. Bech-Otschir, D.; Kraft, R.; Huang, X.; Henklein, P.; Kapelari, B.; Pollmann, C.; Dubiel, W. COP9 signalosome-specific phosphorylation targets p53 to degradation by the ubiquitin system. EMBO J. 2001, 20, 1630. [CrossRef]

54. Kalkhoven, E. CBP and p300: HATs for different occasions. Biochem. Pharmacol. 2004, 68, 1145-1155. [CrossRef] [PubMed]

55. Ariyoshi, M.; Schwabe, J.W.R. A conserved structural motif reveals the essential transcriptional repression function of Spen proteins and their role in developmental signaling. Genes Dev. 2003, 17, 1909. [CrossRef]

56. Liu, Q.; Yao, F.; Wang, M.; Zhou, B.; Cheng, H.; Wang, W.; Jin, L.; Lin, Q.; Wang, J.-C. Novel human BTB/POZ domain-containing zinc finger protein ZBTB1 inhibits transcriptional activities of CRE. Mol. Cell. Biochem. 2011, 357, 405-414. [CrossRef]

57. Serra, R.W.; Fang, M.; Park, S.M.; Hutchinson, L.; Green, M.R. A KRAS-directed transcriptional silencing pathway that mediates the CpG island methylator phenotype. Elife 2014, 3, e02313. [CrossRef] 
58. Kim, H.; Dejsuphong, D.; Adelmant, G.; Ceccaldi, R.; Yang, K.; Marto, J.A.; D'Andrea, A.D. Transcriptional repressor ZBTB1 promotes chromatin remodeling and translesion DNA synthesis. Mol. Cell 2014, 54, 107-118. [CrossRef] [PubMed]

59. Matic, I.; Schimmel, J.; Hendriks, I.A.; van Santen, M.A.; van de Rijke, F.; van Dam, H.; Gnad, F.; Mann, M.; Vertegaal, A.C.O. Sitespecific identification of SUMO-2 targets in cells reveals an inverted SUMOylation motif and a hydrophobic cluster SUMOylation motif. Mol. Cell 2010, 39, 641-652. [CrossRef]

60. Moosmann, P.; Georgiev, O.; Le Douarin, B.; Bourquin, J.P.; Schaffner, W. Transcriptional repression by RING finger protein TIF1 beta that interacts with the KRAB repressor domain of KOX1. Nucleic Acids Res. 1996, 24, 4859-4867. [CrossRef]

61. Wennemers, M.; Bussink, J.; Scheijen, B.; Nagtegaal, I.D.; van Laarhoven, H.W.; A Raleigh, J.; A Varia, M.; Heuvel, J.J.; Rouschop, K.M.; Sweep, F.C.; et al. Tribbles homolog 3 denotes a poor prognosis in breast cancer and is involved in hypoxia response. Breast Cancer Res. 2011, 13, R82. [CrossRef] [PubMed]

62. Orea-Soufi, A.; Castillo-Lluva, S.; Salvador-Tormo, N.; Martín-Cabrera, P.; Recuero, S.; Gabicagogeascoa, E.; Moreno-valladares, M.; Mendiburu-Eliçabe, M.; Blanco-Gómez, A.; Ramos-Pittol, J.M.; et al. The Pseudokinase TRIB3 Negatively Regulates the HER2 Receptor Pathway and Is a Biomarker of Good Prognosis in Luminal Breast Cancer. Cancers 2021, 13, 5307. [CrossRef]

63. King, K.L.; Cidlowski, J.A. Cell Cycle Regulation and Apoptosis1. Annu. Rev. Physiol. 2003, 60, 601-617. [CrossRef] [PubMed]

64. Mata, J.; Curado, S.; Ephrussi, A.; Rorth, P. Tribbles Coordinates Mitosis and Morphogenesis in Drosophila by Regulating String/CDC25 Proteolysis. Cell 2000, 101, 511-522. [CrossRef]

65. Flavin, R.; Peluso, S.; Nguyen, P.L.; Loda, M. Fatty acid synthase as a potential therapeutic target in cancer. Future Oncol. 2010, 6, 551. [CrossRef]

66. Bauer, R.C.; Sasaki, M.; Cohen, D.M.; Cui, J.; Smith, M.A.; Yenilmez, B.O.; Steger, D.J.; Rader, D.J. Tribbles-1 regulates hepatic lipogenesis through posttranscriptional regulation of C/EBP $\alpha$. J. Clin. Invest. 2015, 125, 3809-3818. [CrossRef] [PubMed]

67. Sakamoto, K.M.; Aldana-Masangkay, G.I. The role of HDAC6 in cancer. J. Biomed. Biotechnol. 2011, 2011, 875824. [CrossRef]

68. Lupo, A.; Cesaro, E.; Montano, G.; Zurlo, D.; Izzo, P.; Costanzo, P. KRAB-Zinc Finger Proteins: A Repressor Family Displaying Multiple Biological Functions. Curr. Genomics 2013, 14, 268. [CrossRef]

69. Zhang, P.; Yang, Y.; Qian, K.; Li, L.; Zhang, C.; Fu, X.; Zhang, X.; Chen, H.; Liu, Q.; Cao, S.; et al. A novel tumor suppressor ZBTB1 regulates tamoxifen resistance and aerobic glycolysis through suppressing HER2 expression in breast cancer. J. Biol. Chem. 2020, 295, 14140-14152. [CrossRef]

70. Zhou, S.; Liu, S.; Lin, C.; Li, Y.; Ye, L.; Wu, X.; Jian, Y.; Dai, Y.; Ouyang, Y.; Zhao, L.; et al. TRIB3 confers radiotherapy resistance in esophageal squamous cell carcinoma by stabilizing TAZ. Oncogene 2020, 39, 3710-3725. [CrossRef]

71. Liu, J.; Zhang, W.; Chuang, G.C.; Hill, H.S.; Tian, L.; Fu, Y.; Moellering, D.R.; Garvey, W.T. Role of TRIB3 in regulation of insulin sensitivity and nutrient metabolism during short-term fasting and nutrient excess. Am. J. Physiol.—Endocrinol. Metab. 2012, 303, E908. [CrossRef]

72. Li, K.; Wang, F.; Cao, W.-B.; Lv, X.-X.; Hua, F.; Cui, B.; Yu, J.-J.; Zhang, X.-W.; Shang, S.; Liu, S.-S.; et al. TRIB3 Promotes APL Progression through Stabilization of the Oncoprotein PML-RAR $\alpha$ and Inhibition of p53-Mediated Senescence. Cancer Cell 2017, 31, 697.e7-710.e7. [CrossRef] [PubMed]

73. Corcoran, C.A.; Luo, X.; He, Q.; Jiang, C.; Huang, Y.; Sheikh, M.S. Genotoxic and endoplasmic reticulum stresses differentially regulate TRB3 expression. Cancer Biol. Ther. 2005, 4, 1063-1067. [CrossRef]

74. Kandoth, C.; McLellan, M.D.; Vandin, F.; Ye, K.; Niu, B.; Lu, C.; Xie, M.; Zhang, Q.; McMichael, J.F.; Wyczalkowski, M.A.; et al. Mutational landscape and significance across 12 major cancer types. Nature 2013, 502, 333-339. [CrossRef] [PubMed]

75. Abbas, T.; Dutta, A. p21 in cancer: Intricate networks and multiple activities. Nat. Rev. Cancer 2009, 9, 400. [CrossRef] [PubMed]

76. Fhu, C.W.; Ali, A. Fatty Acid Synthase: An Emerging Target in Cancer. Molecules 2020, 25, 3935. [CrossRef] [PubMed]

77. Prudente, S.; Hribal, M.L.; Flex, E.; Turchi, F.; Morini, E.; De Cosmo, S.; Bacci, S.; Tassi, V.; Cardellini, M.; Lauro, R.; et al. The functional Q84R polymorphism of mammalian Tribbles homolog TRB3 is associated with insulin resistance and related cardiovascular risk in Caucasians from Italy. Diabetes 2005, 54, 2807-2811. [CrossRef] 